\title{
EFEITOS DA DISPOSIÇÃO AMBIENTALMENTE ADEQUADA DOS RESÍDUOS SÓLIDOS URBANOS SOBRE A SAÚDE EM MUNICÍPIOS BRASILEIROS ${ }^{1}$
}

\author{
Carlos Cesar Santejo Saiani² \\ Rodrigo Silva Mendonça ${ }^{3}$ \\ Mônica Yukie Kuwahara ${ }^{4}$
}

0 objetivo deste estudo foi investigar empiricamente se a forma de disposição final dos resíduos sólidos urbanos afeta indicadores municipais de saúde. Por meio de estimações econométricas com dados de municípios brasileiros e paulistas, foram averiguadas e corroboradas as hipóteses da existência e da qualidade dos aterros sanitários e da exportação de resíduos a outros territórios resultarem em melhores indicadores de saúde. Por exemplo, os resultados sinalizaram reduções médias da morbidade hospitalar de 1,25\% associadas à existência de aterros sanitários e de $0,75 \%$ à qualidade destes, com efeitos robustos em crianças e idosos e pelas doenças de veiculação hídrica, mais direta e imediatamente afetadas pela situação do serviço. Tais resultados permitem inferir que a expansão da disposição ambientalmente adequada dos resíduos urbanos é um desafio para as políticas públicas brasileiras, podendo, ao mesmo tempo, reduzir despesas públicas com saúde, poupando recursos para outros fins, e estimular o desenvolvimento humano e sustentável.

Palavras-chave: resíduos sólidos; saúde; meio ambiente; dados em painel.

\section{EFFECTS OF THE ENVIRONMENTALLY APPROPRIATE DISPOSAL OF URBAN SOLID WASTE ON HEALTH IN BRAZILIAN MUNICIPALITIES}

This article aims to investigate empirically whether the form of final disposal of municipal solid waste affects the health indicators. Econometric estimations of data onto Brazilian and São Paulo municipalities verified and corroborated the hypotheses of the existence and quality of sanitary landfills and the exportation of solid waste result in better health indicators. We found a $1.25 \%$ average reduction in hospital morbidity associated with the existence of sanitary landfills and $0.75 \%$ because of their quality. We found robust effects in children, elderly and waterborne diseases, more directly and immediately affected by the service conditions. These results allow us to infer that the expansion of the environmentally sound disposal of urban waste is a challenge to public policies, because it could reduce public health expenditure, saving resources for other purposes, and promoting human and sustainable development.

Keywords: solid waste; health; environment; panel data.

1. DOI: http://dx.doi.org/10.38116/ppp55art8

2. Professor adjunto do Programa de Pós-Graduação em Economia da Universidade Federal de Uberlândia (PPGE-UFU) e do Instituto de Economia e Relações Internacionais da UFU (IERI-UFU). E-mail: <ssaiani@ufu.br>.

3. Analista de planejamento comercial da Tripag Meios de Pagamento Ltda.E-mail:<rodrigosilva.mendonca@hotmail.com>.

4. Professora adjunta no Programa de Pós-Graduação em Economia da Universidade Federal do ABC (PPGE-UFABC).

E-mail: <monica.kuwahara@ufabc.edu.br>. 


\section{EFECTOS DE LA ELIMINACIÓN AMBIENTALMENTE ADECUADA DE LOS RESÍDUOS SÓLIDOS URBANOS EN LA SALUD DE LOS MUNICÍPIOS BRASILEÑOS}

El objetivo de este estudio fue investigar empíricamente si la forma de colocación final de los residuos sólidos urbanos afecta indicadores municipales de salud. Por medio de estimaciones econométricas con datos de municipios brasileños y paulistas, fueron averiguadas y corroboradas las hipótesis de la existencia y calidad de los rellenos sanitarios y que la exportación de residuos a otros territorios resultara en mejores indicadores de salud. Por ejemplo, los resultados mostraron reducciones en promedio de la mortalidad hospitalaria de 1,25\% asociadas a la existencia de rellenos sanitarios y de $0,75 \%$ a la calidad de estos, con efectos robustos en niños y ancianos y por las enfermedades transmitidas por el agua, más directa e inmediatamente afectadas por la situación del servicio. Tales resultados permiten inferir que la expansión de la colocación ambiental apropiada de los residuos urbanos es un desafío para las políticas públicas brasileñas, pudiendo, al mismo tiempo, reducir los gastos públicos en salud, ahorrando recursos para otros fines y estimular el desarrollo humano y sostenible.

Palabras clave: residuos sólidos; salud; medio ambiente; datos en panel.

\section{EFFETS DE L'ELIMINATION ECOLOGIQUEMENT APPROPRIEE DES RESIDUS SOLIDES URBAINS SUR LA SANTE DANS LES MUNICIPALITES BRESILIENNES}

Le but de ce présente étude a été d'examiner de façon empirique si la forme de disposition finale des résidus solides urbains affecte les indicateurs municipaux de santé. À l'aide d'estimations économetriques avec des donnés provennant de communes brésiliennes et pauliste des hypothèses de l'existence e de la qualité des décharges sanitaires et d'exportation de résidus vers d'autres territoires qui aboutissent à meilleurs indicateurs de santé ont été contrôlées et corroborées. Par exemple, les résultats ont indiqué des réductions moyennes de la morbidité hospitalière de 1,25\% associées à l'existence de décharges sanitaires et de 0,75\% à la qualité d'entre ceux-ci avec des effets robustes chez les enfants et chez les personnes âgées et par des maladies hydriques plus direct et immédiatement touchées par la situation du service. Ces résultats permettent de déduire que l'expansion de l'arrangement environnementale approprié des déchets urbains est un défi aux politiques publiques brésiliennes pouvant en même temps réduire les dépenses publiques de santé en économisant des ressources à des fins autres et inciter le développement humain et durable.

Mots-clés: residus solides; santé; environnement; donnees du panneau.

JEL: H42; H53; Q53.

\section{INTRODUÇÃO}

Com uma abordagem multidisciplinar, este estudo explora empiricamente a relação entre resíduos sólidos urbanos e saúde. O objetivo é averiguar se, nos municípios brasileiros, a disposição final ambientalmente adequada destes resíduos influencia a saúde da população. Para isso, são testadas três hipóteses: i) a existência de aterro sanitário, ao refletir, pelo menos parcialmente, a adequação da disposição dos resíduos, melhoraria as condições de saúde dos residentes de um município; ii) a qualidade das instalaçóes de disposição final também impactaria positivamente 
sobre tais condições; e iii) municípios que exportam resíduos para outros municípios, reduzindo impactos ambientais em seus territórios, tenderiam a apresentar melhores indicadores de saúde.

Além da disponibilidade de dados, a análise municipal é justificada pela Lei Federal no 12.305, de 2010 (Lei dos Resíduos Sólidos), que instituiu a Política Nacional de Resíduos Sólidos (PNRS), estabelecendo aos municípios (e ao Distrito Federal) a responsabilidade pela gestão integrada de resíduos sólidos gerados nos seus territórios. A lei também define disposiçáo final ambientalmente adequada como a distribuição ordenada de rejeitos em aterros sanitários, observando normas operacionais específicas para evitar danos ou riscos à saúde e à segurança e para minimizar efeitos ambientais adversos (Brasil, 2010). Ou seja, os possíveis impactos sobre a saúde constam explicitamente como motivaçóes da lei.

Para testar as hipóteses e atingir o objetivo, são feitas algumas estimaçóes econométricas. Primeiro, informaçôes da Pesquisa Nacional de Saneamento Básico (PNSB) de 2008 - última realizada -, do Instituto Brasileiro de Geografia e Estatística (IBGE), são utilizadas para identificar a existência de aterros sanitários nos municípios brasileiros naquele ano e, por meio de regressóes por mínimos quadrados ordinários (MQO), avaliar seus efeitos médios sobre indicadores municipais de morbidade hospitalar (internaçóes) e mortalidade (óbitos), calculados com dados do Departamento de Informática do Sistema Único de Saúde (Datasus), vinculado ao Ministério da Saúde (MS).

Ademais, o método de efeitos fixos é empregado para um painel de municípios paulistas com dados anuais de 2003 a 2011. Neste caso, são empregados dados sobre a qualidade das instalaçốes de disposição e a ocorrência de exportação de resíduos do Inventário Estadual de Resíduos Sólidos Domiciliares da Companhia Ambiental do Estado de São Paulo (Cetesb) para estimar os efeitos destes atributos sobre os indicadores municipais de morbimortalidade.

A literatura de saúde, de modo geral, sinaliza a existência de uma relação positiva entre a cobertura e a qualidade dos serviços de saneamento ambiental - ou básico ${ }^{5}$ - e as condições de saúde da população em uma localidade. Contudo, a maior parte dos trabalhos, em especial para o Brasil, considera apenas o abastecimento de água e/ou esgotamento sanitário, devido à maior disponibilidade de dados. Nesse sentido, especificamente em relação aos serviços de manejo de resíduos sólidos, entre os quais a disposição final dos resíduos urbanos, Forattini (1969), Oliveira (1978), Heller e Catapreta (1997), Mavropoulos (2015), entre outros, ressaltam

5. 0 saneamento básico corresponde ao conjunto de serviços de abastecimento de água (captação, tratamento e distribuição), esgotamento sanitário (coleta, transporte, tratamento e disposição final), manejo dos resíduos sólidos (limpeza urbana, coleta, transporte, tratamento e destinação ou disposição finais), drenagem e manejo de águas pluviais urbanas. Assim, a disposição final de resíduos sólidos urbanos é um dos serviços de manejo de resíduos sólidos, que, por sua vez, é um dos conjuntos de serviços de saneamento básico (Brasil, 2007; 2010). 
que existem poucas evidências na literatura empírica dos impactos diretos destes serviços sobre a incidência de doenças. Porém, Ferreira e dos Anjos (2001) apontam que a literatura médica reconhece a importância do gerenciamento adequado dos resíduos para a saúde. Assim, este estudo apresenta evidências que contribuem para preencher uma lacuna na literatura empírica.

Instalações inadequadas de disposição final dos resíduos sólidos urbanos, como aterros controlados e, principalmente, "lixôes" - ao contrário dos aterros sanitários -, afetam a saúde por meio de seus impactos no meio ambiente. A decomposiçáo dos resíduos a céu aberto, sem medidas de proteção, contamina o solo, também contaminado pelo chorume gerado na decomposição. A contaminação dos solos pode afetar os recursos hídricos (superficiais e subterrâneos), que também são contaminados pelo chorume. Na decomposição, são emitidos, ainda, gases que contaminam o ar. Estes fatores geram ambientes favoráveis à proliferação de doenças. ${ }^{6}$

Contudo, segundo a literatura, há diversos aspectos que dificultam a avaliação dos efeitos da disposição final inadequada dos resíduos sólidos urbanos sobre a saúde. Para comparaçôes entre localidades, como municípios - no caso deste estudo -, existem poucos dados disponíveis que permitem considerar diferentes "fatores de exposição", ou seja, atributos das instalações de disposição que influenciam seus efeitos sobre a saúde, como: i) recebimento de outros tipos de resíduos; ;ii) impermeabilização da base e laterais; iii) cobertura e compactação; iv) coleta e tratamento do chorume e gases; e v) presença de animais e insetos (Mavropoulos, 2015).

Além disso, alguns agravos à saúde não se refletem no curto prazo, mas sim ao longo do tempo, após um processo de bioacumulação no qual o corpo humano, mesmo exposto a baixas quantidades de substâncias nocivas, não as elimina. Estas vão se acumulando e, no decorrer do tempo, resultam em enfermidades (Goldman et al., 1985). Outro aspecto a se considerar é que as doenças são condicionadas por fatores ambientais, mas estes interagem com características individuais e socioeconômicas que influenciam a suscetibilidade das pessoas a contraí-las. Ou seja, são resultantes de uma complexa cadeia causal (Esrey et al., 1990; Heller, 1997).

Diante desses fatos, este artigo adota algumas estratégias empíricas com o intuito de garantir maior robustez na atribuição de causalidade às relaçôes estimadas. A utilização de duas amostras (e dois métodos) é uma das estratégias. Na primeira amostra, são considerados municípios de todo o Brasil; na outra, apenas municípios do estado de São Paulo, mas com variabilidade transversal e longitudinal. Os dados

6. Ver, por exemplo: Goldman et al. (1985), Heller (1997), Heller e Catapreta (1997), Guerreiro e Cairns (2009), Azevedo, Azevedo e Heller (2000), Su (2005), Gouveia (2012), David e Oluyege (2014) e Mavropoulos (2015).

7. A disposição de outros tipos de resíduos sólidos (industriais, da construção civil, agrossilvopastoris, de serviços de saúde, saneamento básico e transporte e da mineração), juntamente com os resíduos urbanos, mesmo em aterros sanitários, não é recomendada em função das especificidades de cada um dos tipos, que demandam formas distintas de acondicionamento que reduzam seus possíveis impactos ambientais adversos (Brasil, 2010). 
da Companhia Ambiental do Estado de São Paulo (Cetesb) sobre a qualidade das instalações de disposição dos resíduos urbanos consideram alguns dos "fatores de exposição" apontados na literatura. É plausível considerar, ainda, os municípios que exportam resíduos como um grupo de controle importante para as análises, pois são o mais próximo possível de uma situação de não geração de resíduos ou, no mínimo, locais nos quais seus impactos negativos tendem a ser menores.

Ademais, em todas as estimações, são controladas várias características socioeconômicas municipais apontadas pela literatura como possíveis determinantes das condiçôes de saúde e da forma de disposição dos resíduos urbanos. Nas estimações em painel, também são controlados efeitos de atributos distintos entre os municípios e constantes no tempo (efeitos fixos), assim como de atributos constantes entre os municípios e variantes no tempo (efeitos fixos temporais).

Deve-se destacar, ainda, a adoção de uma estratégia de identificação fundamentada pela literatura de saúde. Esta estratégia consiste na estimação dos efeitos médios da existência de aterros sanitários, da qualidade das instalações de disposição final e da exportaçáo de resíduos sobre a saúde segundo causas específicas e faixas etárias. Desse modo, são estimados efeitos sobre indicadores de morbimortalidade pelas doenças apontadas como mais direta e imediatamente afetadas pela situação da disposição dos resíduos urbanos - doenças de veiculação hídrica em geral e, mais especificamente, diarreicas - e nas faixas etárias mais vulneráveis a contraírem tais doenças - crianças de até 5 anos. Se os resultados sinalizarem efeitos nestes indicadores e não nos mesmos indicadores, mas por doenças não diretamente associadas à disposição final dos resíduos, são obtidas evidências favoráveis à interpretação como efeitos causais. Por último, vale apontar que o emprego de dois indicadores de saúde (morbidade hospitalar e mortalidade) busca lidar com prováveis erros de mensuração dos dados disponibilizados pelo Datasus.

É interessante antecipar que, pelas estratégias adotadas, os resultados são relativamente robustos, sinalizando que a existência de aterros sanitários e a qualidade adequada das instalaçôes de disposição final reduzem, na média, a morbidademortalidade de crianças e idosos. Estes resultados sugerem a relevância da disposição final ambientalmente adequada dos resíduos urbanos e como este é um desafio para as políticas públicas no Brasil. Segundo Abrelpe (2016), o país gerou, em 2016, cerca de 78 milhôes de toneladas de resíduos urbanos, sendo $91 \%$ coletados e $58 \%$ do total coletado destinado a aterros. Aproximadamente 60\% dos municípios enviam mais de 29 milhóes de toneladas de resíduos urbanos a "lixóes" ou aterros controlados. Em 2007, pela $\mathrm{PNSB}$, mais de $70 \%$ dos municípios não destinavam resíduos urbanos a aterros sanitários. Ou seja, a situação da disposição final só melhorou em pouco mais de $10 \%$ dos municípios, mesmo sendo proibida em "lixóes" e aterros controlados a partir de 2014 pela Lei dos Resíduos Sólidos (Brasil, 2010). O problema tende a se agravar ao longo do tempo, dada a tendência de aumento da geração de resíduos (Gouveia, 2012). 
Vale ressaltar que os baixos investimentos na disposição dos resíduos no Brasil podem ser explicados pela existência de diversos entraves relacionados a: i) escalas, custos e fontes de financiamento; ii) capacidades técnica, institucional e financeira dos titulares; iii) licenciamento ambiental e localização dos aterros - custo da terra; iv) ineficiência dos provedores de outros serviços de manejo de resíduos; e v) motivações políticas (Grisa e Capanema, 2018).

Em termos mais diretos, pode-se inferir que a ausência de disposição final adequada dos resíduos urbanos, ao influenciar a morbidade hospitalar, pode resultar em redução de despesas públicas com saúde (Mavropoulos, 2015). Os recursos economizados com tais despesas poderiam ser alocados a outros tipos de gastos. Em termos mais amplos, este estudo pode se inserir em dois debates que sinalizam a importância de seus resultados para o desenvolvimento.

O primeiro debate refere-se aos efeitos na capacidade de carga do planeta, que, a partir de dado momento, pode restringir o crescimento econômico. Além de poluírem alguns recursos ambientais, os resíduos são materiais de alta entropia, resultantes da transformação de materiais de baixa entropia. Ao longo do tempo, materiais de alta entropia e poluentes se acumulariam e se tornariam uma restrição ao crescimento econômico (Costanza, 1991; Cavalcanti, 1997; Romeiro, 2003; Martinez-Alier e Roca, 2005; Daly e Farley, 2010).

O segundo debate é o do desenvolvimento humano, que, segundo Sen (1996; 2000; 2001), Nussbaum (2011) e Robeyns (2005), deve ser concebido a partir das oportunidades efetivas que cada indivíduo possui, seguindo suas intençôes, para agir e realizar as atividades que deseja. Ou seja, o desenvolvimento humano pode ser definido como o processo de extinção de privaçóes à liberdade. Nesta concepção, a disposição final adequada dos resíduos urbanos pode ser considerada como uma dimensão importante do desenvolvimento humano, pois, ao afetar a saúde e as condiçôes objetivas do se "viver bem" (privaçôes à saúde), também afeta a capacidade de realizar escolhas ao longo da vida (capacitaçóes individuais).

Isso porque diversos trabalhos defendem - e alguns mostram evidências - que a contração de doenças na infância pode prejudicar o desenvolvimento físico e mental e, consequentemente, o desempenho escolar das crianças e, quando adultas, a produtividade no trabalho, o que pode se refletir em menores rendimentos e em outros tipos de privaçóes (Cvjetanovic, 1986; Glewweb e Jacoby, 1995; Alderman et al., 1997; Banerjee e Duflo, 2001).

Considerando-se todos os aspectos comentados, é possível afirmar que a disposição final adequada dos resíduos urbanos é condição necessária para o desenvolvimento sustentável, uma vez que influencia aspectos de seus três pilares ambiental, social e econômico (Romeiro, 2003). Nesse sentido, políticas para o gerenciamento dos resíduos são decisões de saúde, mas é necessária a integração de políticas econômicas, sociais e ambientais (Gouveia, 2012). 
Realizados tais apontamentos iniciais, este artigo se divide em três seçóes, além desta introdução e das consideraçôes finais. $\mathrm{Na}$ seção 2, são discutidos conceitos, aspectos teóricos e evidências que fundamentam opçóes das estratégias empíricas, que são apresentadas na seção 3 . $\mathrm{Na}$ seção 4 , os resultados das estimaçóes econométricas são analisados.

\section{DISPOSIÇÃO FINAL DE RESÍDUOS SÓLIDOS URBANOS E SAÚDE}

Resíduos sólidos são materiais, substâncias, objetos e bens descartados para os quais a destinação final procede nos estados sólido ou semissólido. Rejeitos são resíduos que, esgotadas as possibilidades de tratamento e recuperação por processos tecnológica e economicamente viáveis, a opção é a disposição final. Intrínseca a tais definições está a distinção entre destinação e disposição finais. A primeira refere-se à reutilização, à reciclagem, à compostagem, à recuperação ou ao aproveitamento energético; a outra, ao depósito de rejeitos em aterros sanitários. Destinações e disposiçóes finais são consideradas ambientalmente adequadas se observarem normas para a reduçáo de seus impactos negativos sobre meio ambiente, saúde e segurança (Brasil, 2010).

"Lixão" é um local de disposição dos resíduos no solo, a céu aberto, sem muitas medidas de proteção ambiental. Aterro controlado é uma técnica na qual os resíduos são cobertos por camadas de material inerte, mas sem impermeabilização da base e laterais, extração e queima controlada de gases da decomposição e tratamento dos percolados (chorume). Por outro lado, aterro sanitário é uma técnica de confinamento de rejeitos que, além das medidas apontadas, tem cobertura por argila e materiais inertes (diariamente e final). Como já mencionado, trata-se da técnica mais apropriada para a disposição final dos rejeitos (Feam, 2006; Mavropoulos, 2015).

No Brasil, coleta seletiva, triagem e tratamento são práticas ainda incipientes, dificultando reúso, recuperação e reciclagem. Consequentemente, grande parte dos resíduos sólidos urbanos é destinada a aterros e, principalmente, a "lixões" (Abrelpe, 2016; Silva, 2017) - resíduos propriamente ditos e rejeitos. Assim, neste estudo, considera-se como forma ambientalmente adequada de disposiçáa de resíduos (ou rejeitos) urbanos os aterros sanitários. Vale apontar que resíduos sólidos urbanos são os originários de atividades domésticas urbanas ou da varriçáo e limpeza de logradouros públicos ou de outros serviços de limpeza urbana (Ibama, 2012).

Disposiçóes finais inadequadas dos resíduos sólidos urbanos impactam negativamente o meio ambiente e, consequentemente, a saúde, criando condiçôes favoráveis à proliferação de diversos agentes patogênicos. Resíduos a céu aberto se tornam criadouros de vermes, moscas e outros transmissores de doenças 
contagiosas. O chorume contamina os solos e os recursos hídricos (superficiais e lençóis freáticos). A poluição dos solos pode afetar as fontes de água. Ademais, os resíduos podem ser descartados já contaminados por patógenos em fluídos corporais (fezes, urina, sangue e escarros), alimentando transmissores de patógenos entéricos, como: insetos, roedores, pássaros e mamíferos silvestres. Por outro lado, os gases emitidos na decomposição podem causar ou agravar algumas doenças respiratórias (Su, 2005; Guerriero e Cairns, 2009; Azevedo, Azevedo e Heller, 2000; Gouveia, 2012; David e Oluyege, 2014; Mavropoulos, 2015).

Vale destacar que alguns agravos à saúde, advindos da exposição aos poluentes resultantes da inadequação da disposição dos resíduos, demoram a se concretizarem, como insuficiência hepática, câncer e, especificamente nas crianças, baixo crescimento e desenvolvimento fisiológico. Além disso, agravos surgem mesmo com exposiçáo a pequenas quantidades de substâncias nocivas, devido à bioacumulação. Ou seja, algumas substâncias são absorvidas e permanecem no corpo, se acumulando e, no decorrer do tempo, gerando prejuízos à saúde (Goldman et al., 1985; Mavropoulos, 2015). Este é um dos aspectos que, de acordo com a literatura, dificultam avaliaçóes dos efeitos da situação da disposição final dos resíduos sólidos sobre a saúde.

Ademais, principalmente para comparaçóes entre localidades - no caso deste estudo, municípios -, é difícil obter informaçôes sobre os diversos "fatores de exposiçâa” que afetam a saúde. Mavropoulos (2015) aponta alguns destes fatores: i) composições dos resíduos e dos poluentes - em especial se, mesmo não sendo apropriado, outros tipos de resíduos sólidos forem dispostos juntamente com os resíduos sólidos urbanos; ii) quantidade, duração e frequência da exposição; iii) massas de poluentes liberados nos recursos hídricos e na atmosfera; iv) extensão e persistência da área contaminada; v) concentraçóes e gradientes dos poluentes; vi) quantidade de pessoas mais sensíveis; e vii) profundidade do local de disposição e seu grau de compactação.

Devem-se considerar, ainda, aspectos apontados pela literatura que levam em conta serviços de saneamento básico em geral. De acordo com tal literatura, os serviços de saneamento geram impactos de longo prazo maiores do que açóes de natureza biomédica, em função de benefícios diretos e indiretos. Diretamente, açóes no saneamento diminuem a proliferação de diversas doenças. Indiretamente, tais açóes tendem a influenciar o desenvolvimento de uma localidade, impactando sobre níveis de renda e educação das pessoas, que, por sua vez, afetam a qualidade da alimentação (melhor nutrição), adoçáo de práticas de higiene e investimentos habitacionais, como a adequação das instalações sanitárias. Neste contexto, é mais provável que os indivíduos demandem e consigam exercer pressão sobre os governantes para provisóes mais adequadas. 
A confluência desses fatores gera menor incidência de doenças. Instalaçóes sanitárias e serviços adequados de saneamento básico reduzem a proliferação. Higiene e nutriçáo diminuem a propensão à contração de doenças. Quanto menor a incidência, maior o desenvolvimento do local, o que permite maior arrecadação tributária e redução de despesas públicas com saúde, recursos que podem ser investidos no setor, diminuindo ainda mais a propagação de doenças. ${ }^{8}$

Assim, o desenvolvimento socioeconômico é afetado pela situação do saneamento, mas também a determina, o que justificaria um efeito multiplicador do saneamento sobre a saúde. Embora tal efeito seja defendido no longo prazo, a literatura ressalva que ele tende a ser menor e de difícil mensuraçáo no curto prazo. Isso se dá por sua dependência de alteraçóes integradas em todos os serviços e do alcance em termos populacionais, uma vez que, se não forem universais, mesmo em menor grau, persiste o risco de proliferação de doenças. Ademais, a adequação do saneamento seria condição necessária, mas não suficiente, para a redução de doenças, sendo condicionante intermediário, interagindo com outros, em uma complexa cadeia causal. Desse modo, a maximização dos efeitos de açóes no saneamento sobre a saúde depende da situaçáo em que são ofertados e do uso adequado dos serviços, que são afetados por atributos socioeconômicos dos indivíduos e localidades (Briscoe, Feachem e Rahaman, 1986; Esrey et al., 1990; Heller, 1997).

Diante desses fatos, a literatura defende que avaliaçóes de efeitos mais diretos e imediatos (curto prazo) sobre a saúde do saneamento básico em geral (Cairncross e Feachem, 1990; Heller, 1997; Mara e Feachem, 1999), inclusive da disposição de resíduos urbanos (Su, 2005; Guerriero e Cairns, 2009; David e Oluyege, 2014; Mavropoulos, 2015), sejam realizadas considerando-se as doenças de veiculaçáo hídrica apresentadas no quadro 1, que as divide em categorias e grupos por sintomas, ciclos de vida dos agentes patogênicos e vias de transmissão. Uma discussão mais detalhada sobre cada doença foge do escopo deste estudo. Contudo, baseando-se na literatura, vale reforçar que o saneamento em geral e, especificamente, a disposição final de resíduos urbanos são fundamentais para a redução de suas incidências.

Para comparaçóes entre localidades, a literatura sugere a utilizaçâo de dados de morbidade (casos ou internaçóes) por doenças diarreicas. Tal indicador é defendido devido à sua relevância para a saúde pública, à possibilidade de servir como parâmetro para a adoção de estratégias comuns de controle de uma enfermidade, independentemente de sua causa, e à sensibilidade mais direta e imediata aos seus determinantes. Isto porque, apesar de a diarreia ser sintoma de doenças distintas (quadro 1), as transmissões dos agentes patogênicos são similares: via feco-oral, sem hospedeiro intermediário. O ciclo de contágio envolve a defecação do agente por uma pessoa, que pode infectar outras que ingerirem ou tiverem contato oral com 
alimentos, água, partes do corpo e objetos contaminados. Segundo Briscoe, Feachem e Rahaman (1986), são vantagens do emprego da morbidade diarreica como indicador de saúde para avaliaçóes de efeitos do saneamento básico: validade, confiabilidade, facilidade e menor custo dos mecanismos de determinação e capacidade de resposta a alteraçóes no saneamento. Esrey et al. (1990) reforçam tal argumento, defendendo todos os serviços de saneamento como importantes meios de controle destas doenças.

Heller (1997) discute os meios pelos quais pode ocorrer transmissão de doenças devido à disposição final inadequada dos resíduos urbanos - canais de contato "homem-lixo". O contato pode ocorrer de forma direta, indireta e via vetores de transmissão. Para o autor, tal diversidade de canais dificulta a avaliação de efeitos do serviço, recomendando, então, o emprego de dados de doenças causadas pelo contato direto ou indireto, como as diarreicas. O mesmo é defendido por Azevedo, Azevedo e Heller (2000) em análises específicas para a disposição final de resíduos urbanos.

QUADRO 1

Doenças de veiculação hídrica

\begin{tabular}{|c|c|c|}
\hline Categorias & Grupos de doenças & Doenças \\
\hline \multirow{3}{*}{$\begin{array}{l}\text { Feco-oral } \\
\text { (transmissão hídrica ou } \\
\text { relacionada à higiene) }\end{array}$} & Diarreicas & $\begin{array}{l}\text { Cólera, infecções por salmonela, amebíases, isosporíases, outras infecções } \\
\text { intestinais (bactérias, protozoários ou vírus). }\end{array}$ \\
\hline & Febres entéricas & Febres tifoides e paratifoides. \\
\hline & Outras & Hepatite A, poliomielite, leptospirose, ascaridíase e tricuríase. \\
\hline \multirow[t]{2}{*}{ Inseto vetor } & Procriação na água & $\begin{array}{l}\text { Filariose linfática, malária, doença de chagas, dengue, febre amarela e } \\
\text { leishmanioses. }\end{array}$ \\
\hline & Picada próxima à água & Doença do sono. \\
\hline \multirow{2}{*}{ Contato com a água } & Penetração na pele & Esquistossomose. \\
\hline & Ingestão & Infecções por helmintos, teníase e cisticercose. \\
\hline \multirow{2}{*}{ Relacionadas à higiene } & Doenças dos olhos & Tracoma e conjuntivites. \\
\hline & Doenças da pele & Dermatofitoses e micoses superficiais. \\
\hline
\end{tabular}

Fontes: Cairncross e Feachem (1990); Heller (1997); Mara e Feachem (1999); Su (2005); Guerriero e Cairns (2009); Azevedo, Azevedo e Heller (2000); Mavropoulos (2015), entre outros.

A literatura advoga, ainda, avaliaçôes para a morbidade diarreica em crianças de até 5 anos, que são mais suscetíveis a doenças advindas de problemas no saneamento. Assim, ações no setor afetam diretamente suas condições de saúde. O estágio de desenvolvimento fisiológico (sistema imunológico em formação) as torna mais vulneráveis a infecçôes e ao adoecimento. Crianças também ingerem mais água e alimentos em relação ao peso corpóreo, o que aumenta o risco de adoecimento. Ademais, costumam levar mãos e objetos à boca e permanecerem mais tempo próximas ao chão (Briscoe, Feachem e Rahaman, 1986; Esrey et al., 1990; Wennemo, 1993; Victora, Grassi e Schmidt, 1994; Heller, 1997; Galiani et al., 2005; Mavropoulos, 2015). 
A mortalidade (óbitos) por doenças diarreicas, especialmente em crianças de até 5 anos, é outro indicador muito usado em avaliaçôes de efeitos de serviços de saneamento básico sobre a saúde. Contudo, é importante fazer algumas ressalvas. De acordo com Briscoe, Feachem e Rahaman (1986), indicadores de mortalidade possuem limitaçóes referentes à confiabilidade e à validade dos dados. Nesse sentido, Wennemo (1993) destaca o problema de subnotificação de óbitos, em especial entre os mais pobres, embora considere provável que variaçóes nas probabilidades de subnotificaçóes não sejam significativas para enviesar comparaçóes temporais e entre localidades.

Óbitos de crianças de até 5 anos podem ser divididos em três grupos de mortalidade: i) neonatal (do nascimento ao $27^{\circ} \mathrm{dia}$ ); ii) pós-neonatal ou infantil tardia (do 28을 dia ao primeiro ano); e iii) na infância (do primeiro ao quinto ano). De acordo com Victora, Grassi e Schmidt (1994), a mortalidade neonatal decorre, principalmente, de dificuldades durante a gestação ou no parto (prematuridade, crescimento retardado, malformaçóes congênitas e baixo peso ao nascer). Efeitos deletérios de inadequaçóes do saneamento podem afetar esta mortalidade se causarem morbidade materna na gestação.

A mortalidade pós-neonatal decorre, principalmente, de doenças do complexo diarreia-pneumonia-desnutrição. Esta modalidade de mortalidade é mais sensível às condiçóes dos serviços de saneamento básico, uma vez que, além da influência direta nas diarreicas, há inter-relações entre as doenças do complexo. É comum, por exemplo, que o óbito nesta faixa etária seja diagnosticado pela causa final, mas que a criança tenha sofrido outras doenças que a debilitaram. Assim, o óbito é uma decorrência de causas múltiplas (Scrimshaw, Taylor e Gordon, 1968).

Denominam-se como mortalidade infantil os óbitos dos grupos neonatais e pós-neonatais (até o primeiro ano). Victora, Grassi e Schmidt (1994) apontam que, embora represente pequena parcela da vida humana, é nesta faixa que se concentra a maior parte dos óbitos de crianças e que estas são as mais afetadas pelo saneamento. Na infância (primeiro ao quinto ano), os óbitos tendem a ser menores, uma vez que crianças sofrem menos por agravos na gestação e parto e têm sistemas imunológicos mais desenvolvidos, sendo que as mais propensas morreram no primeiro ano. Desse modo, é possível que crianças de 1 a 5 anos adoeçam devido a inadequaçôes do saneamento, mas o risco de óbito é menor. Portanto, é plausível sugerir que inadequaçôes tendem a afetar mais os óbitos (mortalidade) de crianças de até 1 ano e as internaçóes hospitalares (morbidade) de crianças de 1 a 5 anos.

Por último, vale comentar quais são os segmentos da população, além da questão etária, com risco de exposiçẫo aos efeitos deletérios da disposição inadequada dos resíduos. Ferreira e dos Anjos (2001) apontam seis grupos de risco: i) população sem coleta domiciliar regular, que se desfaz dos resíduos em locais próximos a suas 
residências, criando ambientes deteriorados e propícios à proliferação de doenças; ii) população próxima ao primeiro grupo, que sofre pelo deslocamento dos resíduos por meio das chuvas ou da mobilidade dos vetores; iii) moradores em vizinhanças dos locais de disposição final (quanto piores as condiçóes destes locais, maiores os impactos); iv) catadores de lixo, que entram em contato direto com resíduos e vetores; v) trabalhadores no manejo dos resíduos sólidos; e vi) toda a população, afetada pela contaminação de recursos hídricos e solos. Assim, há risco à saúde para todos que têm contato direto com os resíduos dispostos inadequadamente ou sofrem seus efeitos indiretos (Azevedo, Azevedo e Heller, 2000).

\section{ESTRATÉGIAS EMPÍRICAS}

Para avaliar se a existência de aterro sanitário em um município afeta a saúde de seus residentes, são feitas estimaçôes econométricas para todos os municípios brasileiros com dados disponíveis referentes a 2008, ano da última PNSB do IBGE. Como só é possível identificar a existência de aterro sanitário em tal ano, as estimaçóes são realizadas por $\mathrm{MQO}$ - com erros-padrão robustos. Os modelos baseiam-se na equação (1).

$$
M_{i}=\alpha_{0}+\alpha_{1} A_{i}+\alpha_{2} X_{i}+L_{i}+\varepsilon_{i}
$$

sendo: $M_{i}$ as variáveis dependentes referentes ao município i; $\alpha_{0}$ a constante; $A_{i}$ a variável explicativa de interesse; $\alpha_{1}$ o coeficiente associado a esta variável; $X_{i}$ o vetor de variáveis de controle; $\alpha_{2}$ o vetor de coeficientes associados a estas; $\mathrm{L}_{\mathrm{i}}$ dummies locacionais; e $\varepsilon_{\mathrm{i}}$ o erro.

As variáveis dependentes são: morbidade hospitalar (internações por cem habitantes) e mortalidade (óbitos por cem habitantes). Os dados sobre as internaçóes são disponibilizados pelo Sistema de Informaçóes Hospitalares (SIH), do Sistema Único de Saúde (SUS), por meio do Datasus, vinculado ao MS. Para serem ressarcidas pelas internações, as unidades hospitalares vinculadas ao SUS (públicas e privadas) enviam suas informaçóes aos gestores municipais ou estaduais de saúde, em "Autorizaçóes de Internaçóes Hospitalares" (AIHs). Estas são encaminhadas ao Datasus, que as processa e disponibiliza. Por sua vez, os dados de óbitos são oriundos do Sistema de Informaçóes sobre Mortalidade (SIM). As secretarias municipais e estaduais de saúde coletam dados nas declaraçóes de óbitos registradas em cartórios. Estes dados são encaminhados ao Datasus, que os disponibiliza.

No Brasil, é comum uma pessoa residir em um município, mas ser internada ou ter seu óbito registrado em outro. Como é plausível esperar que sua saúde seja afetada por características da localidade em que reside, os dados de internaçóes e óbitos são coletados segundo o município de residência. Optou-se por calcular indicadores para cada cem habitantes, ao contrário de alguns estudos e estatísticas 
oficiais que utilizam bases superiores, para que sugiram a probabilidade de um residente ser internado ou falecer. É importante fazer ressalvas para esta interpretação: não é possível identificar se uma pessoa foi internada mais de uma vez ou se já estava doente antes de falecer (Funasa, 2002). Os dados sobre população municipal são oriundos do IBGE.

Como já mencionado, a literatura sinaliza certa superioridade na utilização da morbidade para avaliaçóes de efeitos de açóes nos serviços de saneamento básico, como a disposição final de resíduos sólidos urbanos, sobre a saúde. Uma limitação para o indicador de morbidade é que são disponibilizadas informaçôes somente para as internaçóes financiadas pelo SUS. Contudo, estas representam parcela significativa do total (Brasil, 2005; Bittencourt, Camacho e Leal, 2006).

$\mathrm{Na}$ estratégia de identificação, detalhada mais adiante, a morbidade é analisada por causas específicas. As informaçôes sobre as causas podem apresentar problemas decorrentes de erros de diagnósticos, inconsistências, ausência de clareza e lacunas nos prontuários médicos, fatores potencializados por profissionais responsáveis pela codificação e consolidação dos prontuários com pouco treinamento e conhecimento. Além disso, há incentivo adverso dos mecanismos de reembolso dos gastos hospitalares. Pesquisas apontam maior confiabilidade dos dados do SIH para categorias mais agregadas de diagnósticos, em especial doenças com sintomas semelhantes (Mathias e Soboll, 1998; Laurenti, Mello Jorge e Gotlieb, 2004). Tal sugestão é adotada neste trabalho.

$\mathrm{Na}$ mortalidade, erros de diagnósticos ocorrem, mas tendem a ser menores, pois há um documento padronizado para a declaração do óbito e não há o incentivo adverso do reembolso. Porém, apesar de a legislação exigir o registro de todas as mortes e das causas, há subnotificação. Para Laurenti, Mello Jorge e Gotlieb (2004), mesmo que os dados não reflitam bem as condiçóes de saúde de um local em um certo momento, tendências devem ser aceitas. Como já mencionado, Wennemo (1993) defende que a probabilidade de subnotificação não deve variar o suficiente para enviesar comparaçóes temporais e entre localidades, como as realizadas neste estudo. Portanto, diante de tais limitações, o emprego de dois indicadores de saúde garante maior robustez aos resultados.

A variável explicativa de interesse $\left(\mathrm{A}_{\mathrm{i}}\right)$ é a dummy aterro, igual a 1 nos municípios com aterro sanitário em seus territórios em 2008. Se seu coeficiente $\left(\alpha_{1}\right)$ for negativo e significativo, pode-se inferir que a disposição adequada dos resíduos urbanos melhora a saúde das pessoas, resultando em menor morbidade ou mortalidade. Pela PNSB, constata-se que apenas $27 \%$ dos municípios brasileiros possuíam aterros sanitários em 2008. Os dados disponíveis permitem averiguar somente efeitos da existência de aterros, sinalizando parcialmente as condiçóes da disposição final dos resíduos sólidos urbanos. Contudo, também seria interessante 
considerar a qualidade dos aterros sanitários, pois, como já mencionado, várias características destes podem ser "fatores de exposição" que afetam seus impactos sobre a saúde (Mavropoulos, 2015).

Tal avaliação é possível com o Inventário Estadual de Resíduos Sólidos Domiciliares da Cetesb, pesquisa realizada anualmente nos municípios paulistas para investigar as condiçôes das instalaçóes de disposição final dos resíduos sólidos urbanos, considerando as características locacionais, de infraestrutura e operacionais, listadas no quadro 2. Entre estas, constam vários "fatores de exposiçáo" apontados pela literatura, como: i) impermeabilização da base; ii) coleta e tratamento do chorume e dos gases da decomposição; iii) drenagem de águas pluviais; iv) monitoramento das águas subterrâneas; v) composição dos resíduos dispostos - recebimento de outros tipos de resíduos (da saúde e industriais), além dos resíduos urbanos -; vi) cobertura e compactaçáo; vii) presença de animais e insetos; e vii) proximidade a núcleos habitacionais.

A Cetesb utiliza todas as características para calcular o Índice de Qualidade de Aterro de Resíduos (IQR) para cada município. A cada característica é atribuído um peso entre 0 e 5 . Todos os pontos são somados, e o valor (130 no máximo) é dividido por 13. O IQR varia entre 0 e 10, e as instalaçóes de disposição final de resíduos são classificadas em: i) inadequadas (0 a 6,0); ii) controladas (6,1 a 8,0); e iii) adequadas $(8,1$ a 10,0). Na ausência de explicaçóes mais detalhadas pela Cetesb, neste estudo, a classificação inadequada é considerada como correspondente aos "lixões", a controlada, como os aterros controlados; e a adequada, como os aterros sanitários.

Como os inventários da Cetesb são anuais e abrangem todos os municípios paulistas, é possível realizar estimações, baseadas nas equações (2) e (3), por métodos com dados em painel (balanceado e erros-padrão robustos). Nestas, diferentemente das estimaçóes baseadas na equação (1), considera-se uma amostra menor de municípios (645, em vez de 5.418), mas com a possibilidade de controlar efeitos de atributos não observados distintos entre os municípios e constantes ao longo do tempo (efeitos fixos - estimador Within). O teste de Hausman averigua a melhor adequação dos efeitos fixos ante os aleatórios (Greene, 1997; Baltagi, 2001).

$$
\begin{aligned}
& M_{i t}=\beta_{0}+\beta_{1} \operatorname{IQRA}_{i t}+\beta_{2} \mathrm{IQRC}_{i t}+\beta_{3} \mathrm{ER}_{\mathrm{it}}+\beta_{4} \mathrm{X}_{\mathrm{it}}+\mu_{\mathrm{i}}+\epsilon_{\mathrm{it}} \\
& \mathrm{M}_{\mathrm{it}}=\beta_{0}+\beta_{1} \mathrm{IQRA}_{\mathrm{it}}+\beta_{2} \mathrm{IQRC}_{\mathrm{it}}+\beta_{3} \mathrm{ER}_{\mathrm{it}}+\beta_{4} \mathrm{X}_{\mathrm{it}}+\mathrm{T}_{\mathrm{t}}+\mu_{\mathrm{i}}+\epsilon_{\mathrm{it}},
\end{aligned}
$$

sendo: $\mathrm{M}_{\mathrm{i}}$ as variáveis dependentes do município i no ano $t ; \beta_{0}$ a constante; IQRA $A_{i t}$, $\mathrm{IQRC}_{i t}$ e $E R_{i t}$ as variáveis explicativas de interesse; $\beta_{1}, \beta_{2}$ e $\beta_{3}$ os coeficientes destas; $X_{i t}$ o vetor de covariadas; $\beta_{4}$ os coeficientes dos controles; $T_{t}$ a tendência; $\mu_{\mathrm{i}}$ os efeitos fixos; e $\epsilon_{\text {it }}$ o erro. 
QUADRO 2

Características das instalações de disposição de resíduos consideradas pela Cetesb

\begin{tabular}{|c|c|c|}
\hline Locacionais & Infraestruturas & Condições operacionais \\
\hline $\begin{array}{l}\text { - Capacidade de suporte do solo. } \\
\text { - Proximidade de núcleos habitacionais. } \\
\text { - Proximidade de corpos d'água. } \\
\text { - Profundidade do lençol freático. } \\
\text { - Permeabilidade do solo. } \\
\text { - Disponibilidade de material para } \\
\text { recobrimento. } \\
\text { - Qualidade do material de recobri- } \\
\text { mento. } \\
\text { - Condições de sistema viário, trânsito } \\
\text { - Isososso. } \\
\text { - Legalidade visual da vizinhançaca. } \\
\text { Lealização. }\end{array}$ & $\begin{array}{l}\text { - Cercamento da área. } \\
\text { - Portaria/guarita. } \\
\text { - Impermeabilização da base. } \\
\text { - Drenagem de chorume. } \\
\text { - Drenagem de águas pluviais. } \\
\text { - Trator de esteiras ou compativel. } \\
\text { - Outros equipamentos. } \\
\text { - Sistema de tratamento de chorume. } \\
\text { - Acesso à frente de trabalho. } \\
\text { - Vigilantes. } \\
\text { - Sistema de drenagem de gases. } \\
\text { - Controle de recebimento de cargas. } \\
\text { - Monitoramento de águas subterrâ- } \\
\text { - } \text { neas. }\end{array}$ & $\begin{array}{l}\text { - Aspectos gerais. } \\
\text { - Ocorrência de lixo a descoberto. } \\
\text { - Recebimento de lixo. } \\
\text { - Presença de urubus ou gaivotas. } \\
\text { - Presença de moscas em grande } \\
\text { quantidade. } \\
\text { - Presença de catadores. } \\
\text { - Criação de animais (porcos e bois, por } \\
\text { exemplo). } \\
\text { - Descarga de resíduos de serviçcos de } \\
\text { saúde. } \\
\text { - Descarga de resíduos industriais. } \\
\text { - Funcionamento da drenagem pluvial } \\
\text { definitiva. } \\
\text { - Funcionamento da drenagem pluvial } \\
\text { provisória. } \\
\text { - Funcionamento da drenagem de } \\
\text { chorume. } \\
\text { - Funcionamento do sistema de trata- } \\
\text { - mento de chorume. } \\
\text { - Funcionamento do sistema de monito- } \\
\text { ramento de águas subterrâneas. } \\
\text { - Maciência da equipe de vigilância. } \\
\text { Manutenção dos acessos internos. }\end{array}$ \\
\hline
\end{tabular}

Fonte: Cetesb.

Elaboração dos autores.

A primeira variável de interesse $\left(\mathrm{IQRA}_{\mathrm{it}}\right)$ corresponde à dummy IQR-Adequado, igual a 1 nos municípios que em t dispóem seus resíduos sólidos urbanos em aterros em seus territórios classificados como adequados. A segunda (IQRC $\left.\mathrm{Iit}_{\mathrm{it}}\right)$ é a dummy IQR-Controlado, igual a 1 nos municípios que dispóem resíduos em aterros em seus territórios classificados como controlados.

Outro dado importante do inventário da Cetesb é "quais municípios exportam resíduos sólidos urbanos a instalaçóes em territórios de outros municípios”, prática legalmente permitida no país (Brasil, 2010). Considerando tal informação, a última variável de interesse é a dummy exportação de resíduos, igual a 1 nos municípios que destinam resíduos a instalaçôes externas a seus territórios. Assim, os municípios com instalaçốes inadequadas são a base de comparação.

É plausível considerar os municípios que exportam resíduos como um grupo de controle ("placebo") interessante a ser analisado. São uma aproximação de uma situaçáo de não geração de resíduos ou representam razoavelmente locais nos quais seus impactos tendem a ser menores, já que são dispostos externamente. Dessa maneira, é possível que os coeficientes da dummy exportação de resíduos contribuam para a interpretaçấo dos efeitos da qualidade dos aterros como causais. 
Caso os coeficientes estimados associados às variáveis de interesse $\left(\beta_{1}, \beta_{2}\right.$ e $\left.\beta_{3}\right)$ forem negativos e significativos, são encontradas evidências que não refutam as hipóteses de que a qualidade das instalações de disposição final dos resíduos sólidos urbanos nos municípios ou o afastamento deles de seus territórios melhorariam as condiçóes de saúde de seus residentes.

A tendência $\mathrm{T}_{\mathrm{t}}$ (linear) controla efeitos de atributos não observados, constantes entre os municípios e variantes no tempo (efeitos fixos temporais). Por exemplo, pode ocorrer transição epidemiológica - mudanças no tempo nos padróes de saúde, em especial, reduçóes de doenças infecciosas, como é o caso de algumas doenças de veiculação hídrica do quadro 1 (Omram, 2001; Schramm et al., 2004). Alteraçóes macroinstitucionais, por sua vez, podem afetar a saúde em todos os municípios e leis promulgadas no período - como as Leis do Saneamento Básico e dos Resíduos Sólidos (Brasil, 2007; 2010) - podem induzir melhorias no tempo da disposição dos resíduos nos municípios, o que tornaria a tendência colinear à evolução da distribuição dos municípios pelo IQR. A tabela 1 mostra evidências neste sentido, justificando, para garantir robustez, testes sem e com a tendência - equações (2) e (3), respectivamente.

\section{TABELA 1}

Evolução da distribuição dos municípios paulistas, segundo o IQR e a exportação de resíduos (2003-2011)

(Em \% do total)

\begin{tabular}{|c|c|c|c|c|}
\hline \multirow{2}{*}{ Anos } & \multicolumn{3}{|c|}{ IQR } & \multirow{2}{*}{ Exportação de resíduos } \\
\hline & Adequado & Controlado & Inadequado & \\
\hline 2003 & 35,19 & 27,91 & 27,29 & 9,61 \\
\hline 2004 & 33,02 & 28,22 & 28,99 & 9,77 \\
\hline 2005 & 40,62 & 24,65 & 23,41 & 11,32 \\
\hline 2006 & 36,43 & 28,37 & 21,55 & 13,64 \\
\hline 2007 & 35,66 & 28,68 & 20,62 & 15,04 \\
\hline 2008 & 37,05 & 35,35 & 8,37 & 19,22 \\
\hline 2009 & 44,96 & 29,46 & 1,24 & 24,34 \\
\hline 2010 & 43,72 & 26,05 & 4,03 & 26,20 \\
\hline 2011 & 40,62 & 27,75 & 3,88 & 27,75 \\
\hline
\end{tabular}

Fonte: Cetesb.

Elaboração dos autores.

Observa-se, ainda, que as proporçóes de municípios nos grupos de IQRs e exportadores variam no decorrer do tempo. Esta variabilidade transversal e longitudinal é importante para estimar, por efeitos fixos, modelos com dummies como variáveis explicativas. Os efeitos fixos $\left(\mu_{\mathrm{i}}\right)$, além de lidarem com potencial viés de autosseleção por características não observadas constantes no tempo - aspecto que 
é retomado mais adiante -, controlam atributos municipais específicos (climáticos, culturais e relevo, por exemplo) que podem influenciar indicadores de saúde. Caldwell (1990), por exemplo, discute efeitos de atributos fixos sobre a incidência das doenças de veiculação hídrica apresentadas no quadro 1. Adicionalmente, alguns dos "fatores de exposiçáa" que influenciam os efeitos da disposição final dos resíduos sólidos urbanos sobre a saúde podem ser considerados como características fixas não observadas, como: localização, condiçôes geológicas e hidrogeológicas, clima e anos de operação (Mavropoulos, 2015).

Como não é trivial controlar efeitos fixos em cross-sections, nas estimações baseadas em (1) são inseridas dummies locacionais $\left(\mathrm{L}_{\mathrm{i}}\right)$ : capital, região metropolitana, Norte, Nordeste, Sul e Centro-Oeste. O intuito é controlar atributos não observados similares nos municípios que compóem cada grupo locacional, mas distintos entre os grupos. Para a localização no estado, a base de comparação é o conjunto de municípios do interior. Para a localização no país, a base de comparação é o grupo de municípios do Sudeste. Por refletirem atributos fixos no tempo, tais dummies não são consideradas nas estimaçóes em painel, sendo captadas pelos efeitos fixos.

As doenças em geral, inclusive as de veiculação hídrica, são resultantes de uma complexa cadeia causal na qual interagem vários fatores, em especial socioeconômicos (Briscoe, Feachem e Rahaman, 1986; Esrey et al., 1990). Estes fatores podem influenciar os impactos da exposição ao lixo, dificultando avaliaçôes dos efeitos da situação da disposição final de resíduos (Martuzzi, Mitis e Forastiere, 2010; Mavropoulos, 2015). Assim, baseando-se na literatura brevemente revisada na seção 2, é importante controlar alguns fatores de confusão. Além disso, também devem ser controlados possíveis atributos que determinam a situação da disposição final, lidando com potenciais vieses de autosseleção. Ou seja, com a possibilidade de as condições de saúde serem distintas entre os municípios com diferentes formas de disposiçấo, independentemente destas. ${ }^{9}$

O quadro 3 mostra as variáveis de controle $\left(\mathrm{X}_{\mathrm{i}}\right.$ ou $\left.\mathrm{X}_{\mathrm{it}}\right)$ - atributos municipais - utilizadas nas estimaçóes. Nas tabelas A.1 e A.2, são apresentadas estatísticas descritivas para estas variáveis. Primeiramente, vale reforçar que todos os serviços de saneamento afetam, de forma integrada, a saúde. Dessarte, é relevante controlar situações de outros serviços, o que é feito pelas variáveis lixo, água e esgoto. ${ }^{10}$ Estas, segundo a literatura, refletem as coberturas pelas respectivas formas mais adequadas. Ademais, coberturas populacionais são fundamentais à eficácia dos efeitos sobre a saúde. A justificativa é intuitiva: uma pessoa que não possui acesso

9. Discussão fundamentada pela literatura de "tratamento" originária do modelo Roy-Rubin (Roy, 1951; Rubin, 1974). Para mais detalhes sobre como covariadas que também afetam o status do tratamento (no caso, a forma de disposição final) e efeitos fixos lidam com o viés de autosseleção, ver, entre outros, Angrist e Pischke (2009).

10. Dados para calcular estas variáveis são disponibilizados apenas nos anos censitários (2000 e 2010). Optou-se por aplicar as variações anuais médias de 2000 a 2010 para o cálculo dos indicadores nos anos não censitários. 
adequado busca outros meios de obtenção de água e afastamento do esgoto e do lixo, meios estes que podem contaminar solos e recursos hídricos e culminar na proliferação de doenças. No caso do lixo, também é relevante controlar a parcela dos domicílios com coleta adequada de resíduos, por estes serem encaminhados às instalaçōes de disposição final ou, na ausência da coleta, despejados em terrenos e recursos hídricos, aumentando a exposição das pessoas a seus efeitos.

QUADRO 3

Variáveis de controle $\left(\mathbf{X}_{\mathrm{i}}\right.$ ou $\left.\mathbf{X}_{\mathrm{it}}\right)$

\begin{tabular}{|c|c|c|}
\hline Variáveis & Descrições & Fontes \\
\hline Lixo & Percentual de domicílios com coleta de lixo por serviço de limpeza. & \multirow{11}{*}{ IBGE } \\
\hline Água & Percentual de domicílios com abastecimento de água por rede geral. & \\
\hline Esgoto & Percentual de domicílios com coleta de esgoto por rede geral. & \\
\hline PIB per capita & Produto interno bruto per capita ( $\mathrm{R} \$$ mil de 2000 ). & \\
\hline População & População total (milhões de habitantes). & \\
\hline População - menos de 1 ano & População com menos de um ano (milhões de habitantes). & \\
\hline População - 1 a 5 anos & População de 1 a 5 anos (milhões de habitantes). & \\
\hline População - 5 a 15 anos & População de 5 a 15 anos (milhões de habitantes). & \\
\hline População - 15 a 64 anos & População de 15 a 64 anos (milhões de habitantes). & \\
\hline População - mais de 64 anos & População com mais de 64 anos (milhões de habitantes). & \\
\hline Densidade & Densidade demográfica (milhares de habitantes $/ \mathrm{km}^{2}$ ). & \\
\hline Fundamental & Percentual de empregados formais com ensino fundamental ou mais. & \multirow{2}{*}{ MTE } \\
\hline Terciário & Percentual de empregados formais no comércio e nos serviços. & \\
\hline Meritórios ${ }^{1}$ & Despesa com bens meritórios (Percentual total). & \multirow{2}{*}{ MF } \\
\hline Bem-estar $^{2}$ & Despesa com bem-estar (Percentual total). & \\
\hline Imunização & Cobertura das imunizações (Percentual da população-alvo). & \multirow{3}{*}{ MS e IBGE } \\
\hline Leitos do SUS & Leitos em hospitais participantes do SUS (por mil habitantes). & \\
\hline Outros leitos & Leitos em hospitais não participantes do SUS (por mil habitantes). & \\
\hline
\end{tabular}

Fonte: Dados quantitativos de IBGE, MF, MTE e MS.

Elaboração dos autores.

Notas: ${ }^{1}$ Despesas públicas com educação, cultura, habitação, urbanismo, saúde e saneamento.

${ }^{2}$ Despesas públicas com assistência e previdência (Oxley e Martin, 1991).

Obs.: MTE - Ministério do Trabalho e Emprego; MF - Ministério da Fazenda.

O desenvolvimento socioeconômico de um local pode resultar em maior conscientização ambiental e sobre saúde, assim como maiores controles sociais e capacidades de arrecadaçáo e de investimento, o que pode influenciar os serviços de disposição de resíduos urbanos e de saúde. Ademais, estes possuem economias de escala e de densidade. Estes aspectos justificam as variáveis PIB per capita, população, densidade e fundamental como controles para possíveis determinantes 
da situação da disposição dos resíduos ${ }^{11}$ (Burai, Saiani e Kuwahara, 2012; Mavropoulos, 2015; Grisa e Capanema, 2018). Os mesmos atributos podem influenciar a geração de lixo (Campos, 2012; Dias et al., 2012; Abrelpe, 2016) e, diretamente, a saúde das pessoas.

Segundo Wennemo (1993) e Wang (2003), quanto maior a renda, maior (ou melhor) o acesso a alimentos - influenciando estado nutricional e desenvolvimento imunofisiológico - e a medicamentos e serviços de saúde. Tais fatores afetam a vulnerabilidade das pessoas. Além disso, como já mencionado na seção 2 , grande parte das doenças de veiculação hídrica é transmissível por solos, recursos hídricos e objetos contaminados ou por insetos vetores. Desse modo, quanto maior e mais concentrada a população, maior tende a ser a proliferação destas doenças. Deve-se considerar, ainda, que, quanto maior a educação, maior o acesso a informações e, assim, a adoçáo de práticas de higiene que reduzem a proliferaçáo de doenças, potencializando (amenizando), ao mesmo tempo, efeitos positivos (negativos) do saneamento (Caldwell, 1990).

$\mathrm{Na}$ ausência de informações que possibilitem o cálculo da taxa de urbanização de todos os municípios em todos os anos, a variável terciário é uma proxy para a urbanização. Como estas atividades são predominantemente urbanas, é plausível supor que, quanto maior a parcela dos empregados nelas, maior tende a ser a urbanização. Por um lado, justifica-se seu controle pela possível distribuiçẫo desigual de infraestruturas e serviços de saúde entre áreas urbanas e rurais (Wang, 2003). Por outro lado, a variável pode controlar capacidades distintas de arrecadação e de investimento, dado que a base tributária municipal é composta por impostos sobre propriedades urbanas e sobre atividades de serviços (Gomes e MacDowell, 2000).

Alguns trabalhos averiguam as relações entre indicadores de saúde e gastos públicos com seguridade social (previdência, assistência social e saúde) e outras funções que podem afetar a saúde (educação, saneamento básico, habitação, urbanismo e cultura). Tais trabalhos defendem que os gastos, ao beneficiarem segmentos mais pobres da população, reduzem a proporção de pessoas na pobreza e, consequentemente, com problemas de nutrição e sem acesso a serviços e bens de saúde, diminuindo, desta forma, a propensão a ficarem doentes (Wennemo, 1993; Wang, 2003). As variáveis bens meritórios e bem-estar buscam controlar estes possíveis impactos.

Segundo Wang (2003), a imunização a doenças é uma importante ação preventiva. Assim, a cobertura vacinal pode influenciar as condiçôes de saúde das pessoas, o que é controlado pela variável imunização. As variáveis leitos SUS e outros

11. As populações segundo idades são utilizadas nas estimações por faixas etárias discutidas mais adiante (estratégia de identificação). Nestas, o controle pela população total é substituído pela população da respectiva faixa etária, uma vez que as análises passam a ser em relação à incidência de doenças em cada uma das faixas. 
leitos são proxies para a disponibilidade de serviços de tratamento de agravos à saúde, que influenciam diretamente a saúde das pessoas em uma localidade (Wennemo, 1993). A desagregaçáo em dois tipos busca controlar o modo predominante da gestão dos serviços (pública ou privada), o que pode resultar em diferenciais de eficiência e eficácia e, consequentemente, impactar sobre a saúde (Souza, Nishijima e Rocha, 2010).

Apesar de o controle por atributos não observados distintos, entre os municípios e fixos no tempo (efeitos fixos); por atributos não observados fixos, entre os municípios e variantes no tempo (variável tendência); e por atributos observados variantes no tempo, entre os municípios (variáveis de controle), é importante lidar com a possibilidade de viés de autosseleção por atributos não observados e variantes entre os municípios e no tempo. Para isso, é adotada uma estratégia de identificação fundamentada pela literatura de saúde revisada na seção 2: estimaçóes dos efeitos médios da situação da disposição final dos resíduos segundo causas específicas e faixas etárias. ${ }^{12}$ Parte-se do pressuposto de que, se for observado um efeito médio nas doenças mais direta e imediatamente afetadas pela situaçáo de disposição dos resíduos sólidos urbanos e nas faixas etárias mais vulneráveis, ele pode ser interpretado, com maior robustez, como causal.

Vale resgatar os aspectos já discutidos da literatura que embasam tal estratégia. Primeiro, que o aterro sanitário é uma forma de disposição final, ambientalmente adequada, dos resíduos urbanos, sendo que sua ausência ou inadequação contribui para a incidência de várias doenças. Porém, há um conjunto que é mais direta e imediatamente afetado: as doenças de veiculação hídrica (quadro 1). Por isso, estas são recomendadas para avaliaçóes de efeitos como as deste estudo. $\mathrm{Na}$ verdade, há trabalhos que defendem um subgrupo mais restrito: doenças diarreicas. Isto porque a diarreia é um sintoma de etiologias distintas, mas, no geral, com transmissão feco-oral, sem hospedeiros intermediários. Outra vantagem é a diarreia ser um sintoma similar de doenças distintas. Em vista disso, segue-se a sugestão da literatura, já reportada nesta seção, de utilizar categorias mais agregadas de doenças para suavizar possíveis erros nos dados do Datasus.

Outra recomendação da literatura é avaliações com indicadores de morbimortalidade de crianças de até 5 anos. Nesta faixa etária, elas são mais vulneráveis às doenças de veiculação hídrica, de modo que inadequaçóes da disposição final dos resíduos urbanos, que resultem em contaminação dos solos ou recursos hídricos, afetam mais direta e imediatamente sua saúde. Há trabalhos que subdividem as crianças mais vulneráveis em duas faixas: menos de 1 ano; e de 1 a 5 anos. Até o primeiro ano, os óbitos seriam mais afetados; do primeiro ao quinto ano, tenderiam a ser menores, pois as crianças sofrem menos por problemas no parto ou durante

12. Estratégia similar à de Galiani et al. (2005) para avaliar efeitos da privatização do saneamento na Argentina. 
a gestação, seus sistemas imunológicos são mais desenvolvidos e as mais propensas já faleceram. Assim, é possível que, do primeiro ao quinto ano, crianças fiquem doentes, mas o risco de óbito é menor. Há, ainda, a chance de o óbito até o primeiro ano ser diagnosticado pela causa final, mas terem sido múltiplas as causas. A agregação das duas faixas poderia, então, enviesar análises (Scrimshaw, Taylor e Gordon, 1968; Victora, Grassi e Schmidt, 1994).

Portanto, para garantir maior robustez na atribuição de causalidade aos efeitos estimados, são averiguados impactos da existência de aterros sanitários, da qualidade das instalaçóes de disposição final dos resíduos sólidos urbanos e da exportação destes resíduos sobre indicadores municipais de morbidade hospitalar e de mortalidade por causas específicas em faixas etárias distintas. Os modelos também se baseiam nas equaçóes (1) e (2), com os respectivos métodos e amostras, com as variáveis dependentes $\left(\mathrm{M}_{\mathrm{i}} \mathrm{e} \mathrm{M}_{\mathrm{it}}\right)$ passando a ser a morbidade (internaçóes) e a mortalidade (óbitos) por grupos de doenças em diferentes faixas etárias. Pelo mesmo motivo das análises totais, estes indicadores são considerados para 100 habitantes da respectiva faixa.

Os três grupos de doenças analisados são: diarreicas, demais hídricas e outras. As doenças dos dois primeiros grupos constam no quadro 1; as doenças do terceiro grupo são todas as que resultam em óbitos e internaçôes, excetuando-se hídricas, neoplasias e respiratórias - ou seja, aquelas não associadas diretamente na literatura a problemas na disposição dos resíduos. As neoplasias e as doenças do aparelho respiratório são desconsideradas da análise devido ao fato de, mesmo podendo ser influenciadas pela inadequação da disposição dos resíduos, tais impactos seriam no decorrer do tempo, em decorrência da bioacumulação de substâncias no corpo (Goldman et al., 1985; Mavropoulos, 2015) - o que já foi comentado anteriormente. Por seu turno, as cinco faixas etárias avaliadas são: menos de 1 ano; de 1 a 5 anos; de 5 a 15 anos; de 15 a 64 anos; e mais de 64 anos.

Primeiramente, são estimados os efeitos médios da existência de aterros sanitários, da qualidade da disposição final e da exportação de resíduos sólidos urbanos sobre indicadores de morbidade hospitalar e de mortalidade por doenças diarreicas e demais hidricas em todas as faixas etárias. Naquelas em que o efeito médio for significativo, são realizadas estimações para o mesmo indicador pelas outras doenças. Se os resultados seguirem o padrão esperado pela literatura, podem ser interpretados, com maior robustez, como efeitos causais. Ou seja, se forem constatados efeitos nos indicadores que consideram doenças hídricas, em especial as diarreicas, nas faixas etárias mais vulneráveis (menores de 5 anos), assim como ausência ou diferença dos efeitos sobre os indicadores de saúde referentes a outras doenças nas mesmas faixas etárias. 


\section{ANÁLISE DOS RESULTADOS}

Devido ao escopo deste estudo, os coeficientes estimados das variáveis de controle não são reportados, podendo ser obtidos com os autores, de modo que o texto subsequente apresenta apenas a análise dos coeficientes associados às variáveis de interesse. Por serem dummies, se significativos, os coeficientes devem ser interpretados como internaçóes ou óbitos, na média, superiores ou inferiores aos dos municípios com disposição final inadequada dos resíduos urbanos. Antes dos resultados das estimaçóes, para auxiliar as análises, a tabela 2 apresenta os valores médios, nas duas amostras, dos indicadores de morbidade e mortalidade considerados mais relevantes.

TABELA 2

Indicadores médios de morbidade e de mortalidade, segundo os tipos de doenças de veiculação hídrica e as faixas etárias - Brasil (2008) e São Paulo (2003-2011)

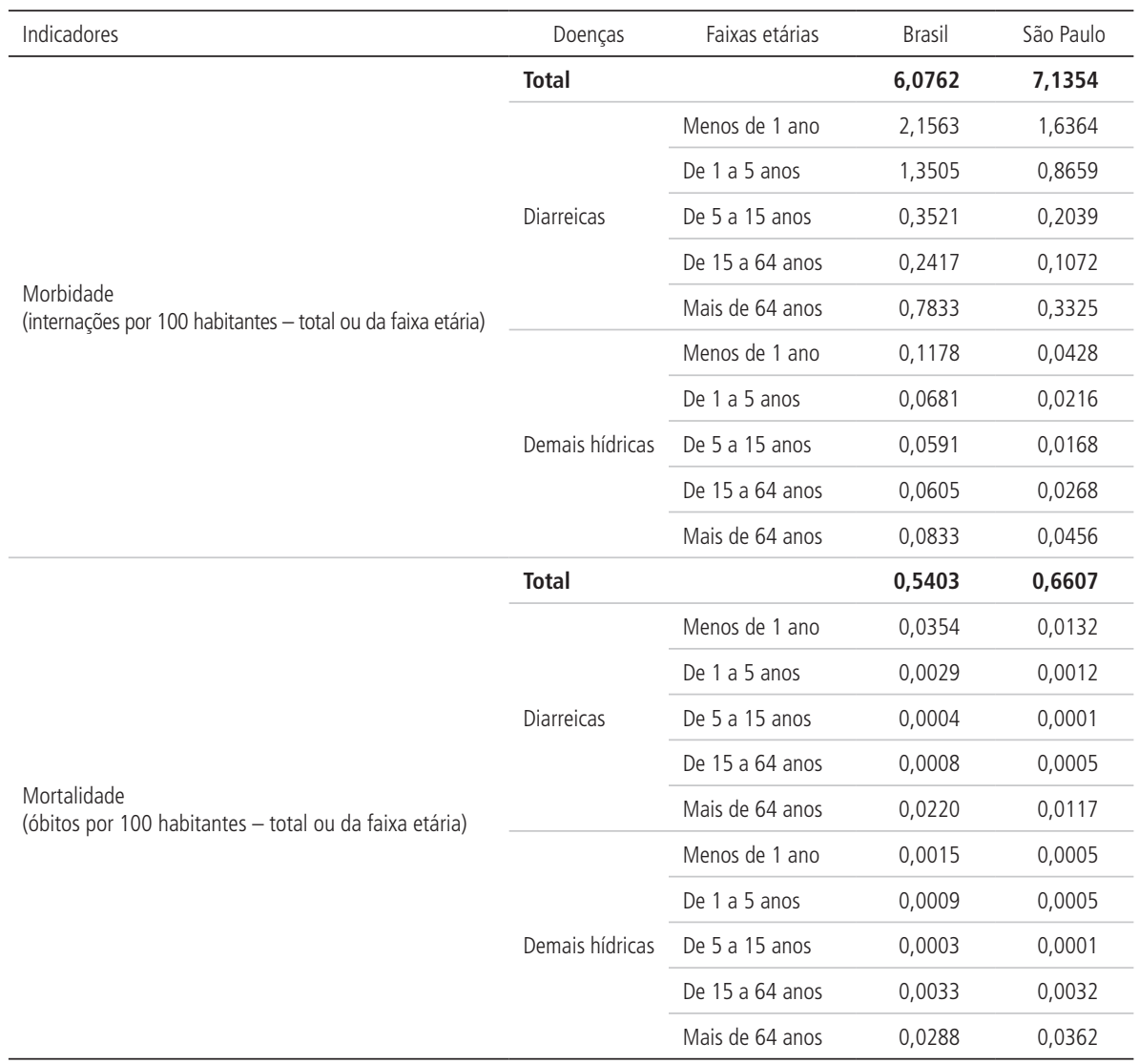

Fonte: Datasus/MS.

Elaboração dos autores. 
A tabela 3 apresenta os resultados das estimaçóes (MQO), para os municípios brasileiros em 2008, referentes às variáveis dependentes morbidade hospitalar e mortalidade. Observa-se que os coeficientes associados à dummy aterro são negativos e significativos. Na morbidade, é significativo a $5 \%$ e representa que, nos municípios que possuem aterros sanitários em seus territórios, ocorrem, na média, 0,0758 internações por 100 habitantes a menos do que nos demais municípios. Considerando-se a morbidade média da amostra, igual a 6,0762 (tabela 2), este efeito corresponde a uma redução média de aproximadamente 1,25\% internação por cem habitantes.

$\mathrm{Na}$ mortalidade, o coeficiente da dummy aterro também é negativo e significativo $(10 \%)$, sinalizando que, nos municípios com aterros sanitários, ocorrem, na média, 0,0064 óbito por 100 habitantes a menos do que naqueles sem aterros. Confrontando com a mortalidade média da amostra - igual a 0,5403 (tabela 2) -, este efeito representa uma redução média de $1,18 \%$.

Os resultados para a morbidade hospitalar e a mortalidade segundo grupos de doenças de veiculação hídrica e faixas etárias são apresentados nas tabelas 4 e 5, respectivamente. Na morbidade por doenças diarreicas, os coeficientes da dummy aterro, na segunda ( 1 a 5 anos) e na última (mais de 64 anos) faixa etária, são negativos e significativos. $\mathrm{O}$ efeito médio na infância é um total de internações por 100 habitantes de 0,0931 caso a menos. Nos idosos, o efeito médio é de $-0,0679$ internação por cem habitantes. Considerando-se os respectivos indicadores médios da amostra - iguais a 1,3505 e 0,7833 (tabela 2) -, estes efeitos médios representam reduçōes médias de, respectivamente, $6,89 \%$ e $8,67 \%$ das internaçóes por 100 habitantes da faixa etária. É observado, ainda, um coeficiente negativo e significativo (a $1 \%$ ) associado à dummy aterro no caso da morbidade hospitalar por demais doenças hidricas na quarta faixa etária (15 a 64 anos).

TABELA 3

Efeitos da existência de aterros sobre a morbidade e a mortalidade (MQ0) - Brasil (2008)

\begin{tabular}{|c|c|c|}
\hline Variáveis & Morbidade & Mortalidade \\
\hline Aterro & $\begin{array}{r}-0,0758^{* *} \\
(0,0303)^{1}\end{array}$ & $\begin{array}{l}-0,0064^{*} \\
(0,0036)^{1}\end{array}$ \\
\hline Controles & $\operatorname{sim}$ & Sim \\
\hline Dummies locacionais & Sim & Sim \\
\hline Constantes & Sim & Sim \\
\hline Observações & 5.418 & 5.418 \\
\hline Prob $>F$ & 0,0000 & 0,0000 \\
\hline$R^{2}$ & 0,1335 & 0,3371 \\
\hline
\end{tabular}

Fonte: Dados quantitativos de IBGE, MF, MTE e MS.

Elaboração dos autores.

Nota: ${ }^{1}$ Erros-padrão robustos.

Obs.: *significativo a 10\%; ** significativo a $5 \%$; e ${ }^{* * *}$ significativo a $1 \%$. 
$\mathrm{Na}$ mortalidade por doenças diarreicas, entretanto, os coeficientes estimados associados à dummy aterro são negativos, e significativos na segunda ( 1 a 5 anos) e na última (mais de 64 anos) faixa etária. Nas crianças, o efeito médio é de -0,0009 óbito por cem habitantes, ou seja, uma redução média de 31\% - tomando como base de comparação o respectivo indicador médio $(0,0029)$ da amostra (tabela 2$)$. Nos idosos, o efeito médio é de -0,0041 óbito por cem habitantes. Considerando-se a mortalidade média desta faixa etária na amostra - 0,0220 (tabela 2), tal efeito médio representa uma redução média de 18,64\% internaçôes por 100 habitantes dessa faixa etária. Verifica-se, ainda, um efeito negativo e significativo (5\%) na mortalidade por demais hídricas na quarta faixa etária.

Portanto, é possível interpretar, com certa robustez, os efeitos médios negativos da dummy aterro como causais. Primeiro, por terem sido significativos nos dois indicadores de saúde (morbidade e mortalidade), pelas mesmas doenças de veiculação hídrica e nas mesmas faixas etárias (segunda, quarta e quinta). Em segundo lugar, por não terem sido observados coeficientes significativos associados à dummy aterro, nestas faixas etárias, nas outras doenças, como é mostrado na tabela 6 . Portanto, os resultados são favoráveis à estratégia de identificação adotada, não refutando a atribuição de causalidade: coeficientes negativos e significativos para as doenças mais direta e imediatamente afetadas pela situação da disposição dos resíduos urbanos (diarreicas) e na faixa etária mais vulnerável (até 5 anos). Vale ressalvar que, na mortalidade, existe significância nas crianças de 1 a 5 anos, mas não nas de até 1 ano, como seria esperado pela revisão da literatura da seção 2. Uma possível explicação, também apontada na seção, seria o problema de diagnóstico do óbito pela causa final, e não pelas múltiplas causas que debilitaram a criança.

Outro aspecto também já comentado é que, entre os principais grupos populacionais de risco, estão os catadores de lixo e os funcionários que lidam diretamente com o manejo de resíduos sólidos urbanos. É plausível supor que estes grupos sejam compostos, predominantemente, por adultos e idosos, o que pode explicar, ao menos parcialmente, os efeitos médios negativos na quarta e na quinta faixa etária. Ademais, idosos tendem a possuir sistemas imunológicos mais debilitados, o que pode contribuir para que estes contraiam doenças (Geib, 2012). Explicaçóes mais detalhadas fogem do escopo deste estudo. O fato importante a ressaltar é que os resultados sinalizam que a existência de aterro sanitário em um município, ao refletir, pelo menos em parte, a adequação da disposição final dos resíduos sólidos urbanos, melhora as condições de saúde dos residentes. 


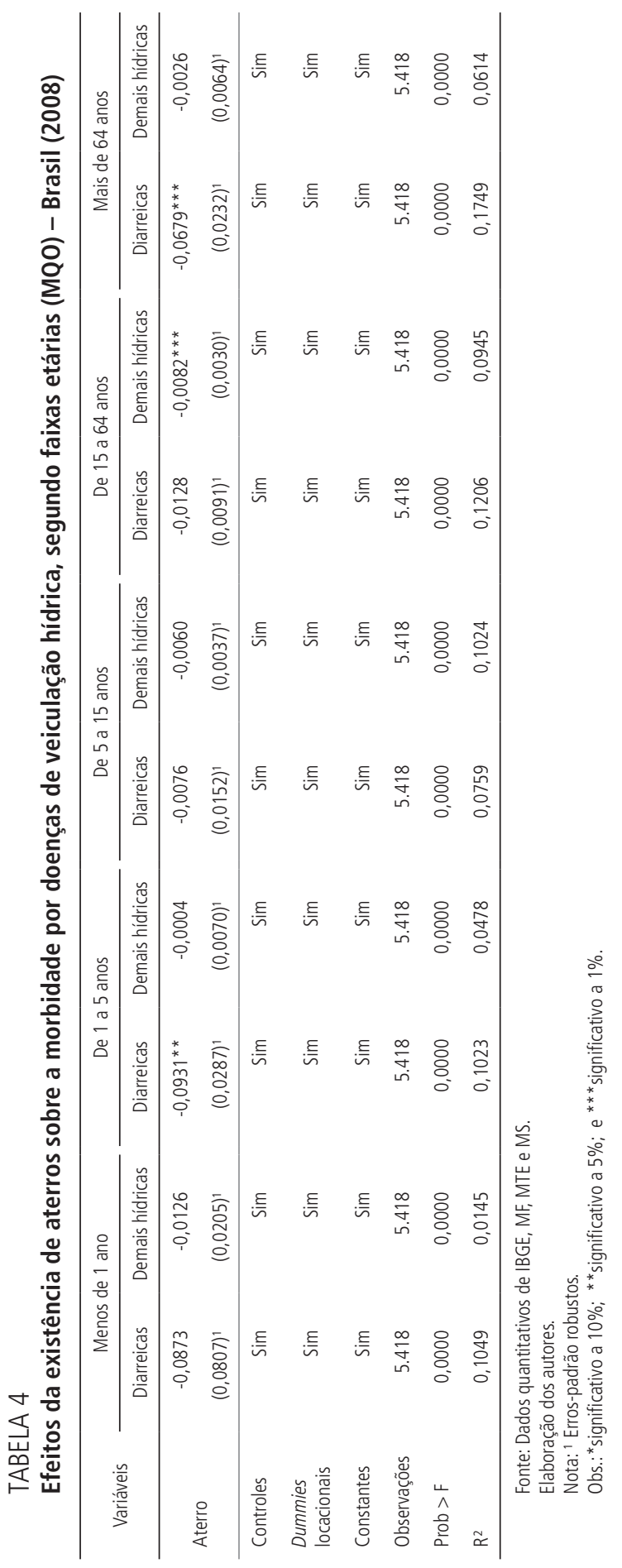




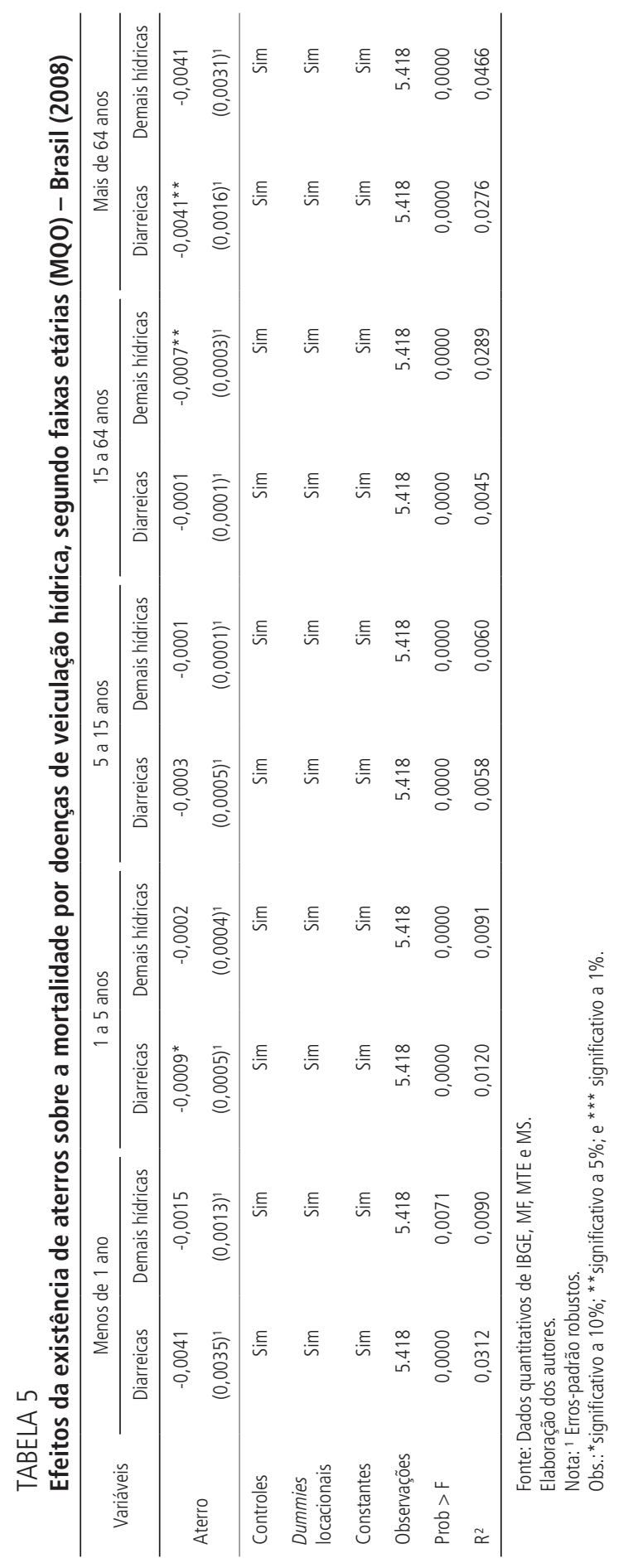


TABELA 6

Efeitos da existência de aterros sobre morbidade e mortalidade por outras doenças, segundo faixas etárias (MQO) - Brasil (2008)

\begin{tabular}{|c|c|c|c|c|c|c|}
\hline \multirow[b]{2}{*}{ Variáveis } & \multicolumn{3}{|c|}{ Morbidade } & \multicolumn{3}{|c|}{ Mortalidade } \\
\hline & $\begin{array}{c}\text { De } 1 \text { a } 5 \\
\text { anos }\end{array}$ & $\begin{array}{c}\text { De } 15 \text { a } 64 \\
\text { anos }\end{array}$ & Mais de 64 anos & De 1 a 5 anos & $\begin{array}{c}\text { De } 15 \text { a } 64 \\
\text { anos }\end{array}$ & Mais de 64 anos \\
\hline \multirow{2}{*}{ Aterro } & 0,0587 & 0,0656 & 0,2977 & $-0,0003$ & $-0,0027$ & 0,0107 \\
\hline & $(0,0991)^{1}$ & $(0,0603)^{1}$ & $(0,2250)^{1}$ & $(0,0037)^{1}$ & $(0,0037)^{1}$ & $(0,0368)^{1}$ \\
\hline Controles & Sim & Sim & Sim & Sim & Sim & Sim \\
\hline Dummies Locacionais & Sim & Sim & Sim & Sim & Sim & Sim \\
\hline Constantes & Sim & Sim & Sim & Sim & Sim & $\operatorname{Sim}$ \\
\hline Observações & 5.418 & 5.418 & 5.418 & 5.418 & 5.418 & 5.418 \\
\hline Prob $>F$ & 0,0000 & 0,0000 & 0,0000 & 0,0000 & 0,0000 & 0,0000 \\
\hline$R^{2}$ & 0,1161 & 0,0903 & 0,1563 & 0,0113 & 0,1690 & 0,1706 \\
\hline
\end{tabular}

Fonte: Dados quantitativos de Cetesb, IBGE, MF, MTE e MS.

Elaboração dos autores.

Nota: ${ }^{1}$ Erros-padrão robustos.

Obs.: * significati2vo a $10 \%$; ** significativo a $5 \%$; e ***significativo a $1 \%$.

A tabela 7 apresenta os resultados das estimações em painel para os municípios paulistas com a morbidade hospitalar e a mortalidade como variáveis dependentes. A especificação I, que corresponde à equação (2), é a base para as análises; por outro lado, a especificação II corresponde à equação (3), na qual é controlada a variável tendência para averiguar a robustez dos resultados. O primeiro aspecto a ser apontado é que, em todas as estimaçóes, o teste de Hausman sinaliza o método de efeitos fixos como mais adequado em comparação ao método de efeitos aleatórios. ${ }^{13}$

TABELA 7

Efeitos da qualidade dos aterros e da exportação de resíduos sobre a morbidade e a mortalidade (painel com efeitos fixos) - São Paulo (2003-2011)

\begin{tabular}{|c|c|c|c|c|}
\hline \multirow{2}{*}{ Variáveis } & \multicolumn{2}{|c|}{ Morbidade } & \multicolumn{2}{|c|}{ Mortalidade } \\
\hline & I & ॥ & I & ॥ \\
\hline \multirow{2}{*}{ IQR-Adequado } & $-0,0295^{* *}$ & $-0,0441 * *$ & $-0,0033$ & $-0,0002$ \\
\hline & $(0,0140)^{1}$ & $(0,0199)^{1}$ & $(0,0044)^{1}$ & $(0,0063)^{1}$ \\
\hline \multirow{2}{*}{ IQR-Controlado } & $-0,0240$ ** & $-0,0225^{* *}$ & $-0,0118$ & $-0,0087$ \\
\hline & $(0,0115)^{1}$ & $(0,0107)^{1}$ & $(0,0255)^{1}$ & $(0,0108)^{1}$ \\
\hline \multirow{2}{*}{ Exportação de resíduos } & $-0,2036$ ** & $-0,1098^{* *}$ & $-0,0050$ & $-0,0037$ \\
\hline & $(0,0969)^{1}$ & $(0,0494)^{1}$ & $(0,0067)^{1}$ & $(0,0050)^{1}$ \\
\hline Controles & Sim & Sim & Sim & Sim \\
\hline Tendência & Não & $\operatorname{sim}$ & Não & Sim \\
\hline
\end{tabular}

13. Por isso, não são reportados os resultados por efeitos aleatórios, que podem ser obtidos com os autores. 


\begin{tabular}{|c|c|c|c|c|}
\hline \multirow{2}{*}{ Variáveis } & \multicolumn{2}{|c|}{ Morbidade } & \multicolumn{2}{|c|}{ Mortalidade } \\
\hline & I & $\|$ & I & $\|$ \\
\hline Constantes & Sim & Sim & Sim & Sim \\
\hline Observações & 5.805 & 5.805 & 5.805 & 5.805 \\
\hline Prob $>F$ & 0,0000 & 0,0000 & 0,0000 & 0,0000 \\
\hline $\mathrm{R}^{2}$ (overall) & 0,0022 & 0,0186 & 0,0122 & 0,0127 \\
\hline Teste de Hausman & $267,69^{* * *}$ & $302,79 * * *$ & $190,47^{* * *}$ & $131,02^{* * *}$ \\
\hline
\end{tabular}

Fonte: Dados quantitativos de Cetesb, IBGE, MF, MTE e MS.

Elaboração dos autores.

Nota: ${ }^{1}$ Erros-padrão robustos.

Obs.: * significativo a $10 \%$; ${ }^{* *}$ significativo a $5 \%$; e ${ }^{* * *}$ significativo a $1 \%$.

$\mathrm{Na}$ mortalidade, todos os coeficientes estimados associados às variáveis de interesse para este estudo não são estatisticamente significativos. Na morbidade, os coeficientes são negativos e significativos (5\%), o que é constatado com ou sem a variável tendência. Na especificaçâo $I$, o coeficiente associado à dummy IQR-Adequado sinaliza 0,0295 internaçóes por 100 habitantes a menos do que nos municípios com IQR inadequado; o coeficiente associado à dummy IQR-Controlado é igual a -0,0240 internaçôes por 100 habitantes; e o coeficiente associado à dummy exportação de resíduos é igual a -0,2036 internações por 100 habitantes. Como a morbidade hospitalar média da amostra é igual a 7,1354 (tabela 2), os efeitos estimados correspondem a reduçóes médias das internaçóes por 100 habitantes de $0,41 \%, 0,34 \%$ e $2,85 \%$, respectivamente.

As tabelas 8 e 9 apresentam os resultados das estimaçóes para a morbidade hospitalar e a mortalidade pelos grupos de doenças de veiculação hídrica e faixas etárias. Na mortalidade, os coeficientes estimados associados às variáveis de interesse não são significativos. $\mathrm{O}$ mesmo é observado na morbidade hospitalar por demais doenças hidricas. Em contrapartida, na morbidade por doenças diarreicas, são observados coeficientes negativos e significativos associados às três variáveis dummies de interesse em três faixas etárias: menos de 1 ano, de 1 a 5 anos e mais de 64 anos.

Nas crianças menores de 1 ano, o coeficiente associado à dummy IQR-Adequado é igual a -0,3782 internação por 100 habitantes da faixa etária; o coeficiente associado à dummy IQR-Controlado é igual a -0,2827; e o coeficiente associado à dummy exportaçâo de residuos é igual a -0,3974. Ou seja, em todos os grupos de municípios, tal morbidade é, na média, menor do que nos municípios com IQR inadequado. Tomando como comparação a morbidade média da faixa etária na amostra - 1,6364 (tabela 2) -, os efeitos estimados representam reduçóes médias das internaçôes (por 100 habitantes da faixa etária) de 23,1\%, 17,3\% e $24,3 \%$, respectivamente. 
Por outro lado, nas crianças de 1 a 5 anos, o coeficiente estimado associado à dummy IQR-Adequado é igual a $-0,1105$ internação por 100 habitantes da faixa etária; o coeficiente associado à dummy IQR-Controlado é igual a -0,1058; e o coeficiente associado à dummy exportação de resíduos é igual a -0,1529. Portanto, em todos os grupos de municípios considerados pelas dummies, a morbidade em análise é, na média, inferior à dos municípios com IQR inadequado. Levando-se em conta o indicador médio da amostra - igual a 0,8659 (tabela 2) -, os efeitos estimados correspondem a reduçóes médias da morbidade de 12,8\%, 12,2\% e $17,7 \%$, respectivamente.

A tabela 10 mostra que, nas crianças (com menos de 1 ano e de 1 a 5 anos) e nos idosos (com mais de 64 anos), não são observados efeitos médios estatisticamente significativos associados às dummies de interesse sobre a morbidade por doenças não direta e imediatamente afetadas pela situação da disposiçáo final dos resíduos sólidos urbanos. Assim, mesmo não sendo constatados efeitos médios sobre a mortalidade, considerando a estratégia de identificação adotada, podem ser interpretadas como causalidades, com certa robustez, as relaçóes negativas entre morbidade, qualidade dos aterros e exportação de resíduos. Isto porque os resultados são significativos no indicador de saúde apontado pela literatura como melhor para tal tipo de avaliação (morbidade), nas doenças mais afetadas (diarreicas) e na faixa etária mais vulnerável (abaixo de 5 anos).

Outros aspectos garantem robustez à atribuição de causalidade. $\mathrm{O}$ primeiro é a evidência de que, quanto melhor a qualidade da instalação utilizada para a disposição final dos resíduos urbanos, menores as internaçóes de residentes (total e por doenças diarreicas, em crianças e idosos). Tal fato pode ser constatado ao serem comparados os coeficientes estimados associados às dummies IQR-Adequado e $I Q R$-Controlado: o efeito médio da situação adequada é sempre maior. Além disso, os coeficientes associados à dummy exportação de resíduos são superiores. Assim, a morbidade (por 100 habitantes) é, na média, inferior nos municípios que destinam resíduos sólidos urbanos a instalaçōes em outros territórios. Ou seja, em municípios nos quais os impactos dos resíduos tendem a ser menores por estes serem acondicionados externamente.

Por último, vale destacar que a qualidade da disposição final dos resíduos urbanos e a exportação destes relacionam-se à morbidade por doenças diarreicas nas crianças e nos idosos. Ou seja, no indicador e nas mesmas faixas etárias para as quais são observados, nas primeiras estimações (tabelas 4 e 5), efeitos da existência de aterros sobre a morbidade - e, naquele caso, mortalidade. Dessa forma, em conjunto, todos os resultados permitem afirmar, com relativa robustez, que a disposição ambientalmente adequada dos resíduos urbanos melhora a saúde das pessoas. 


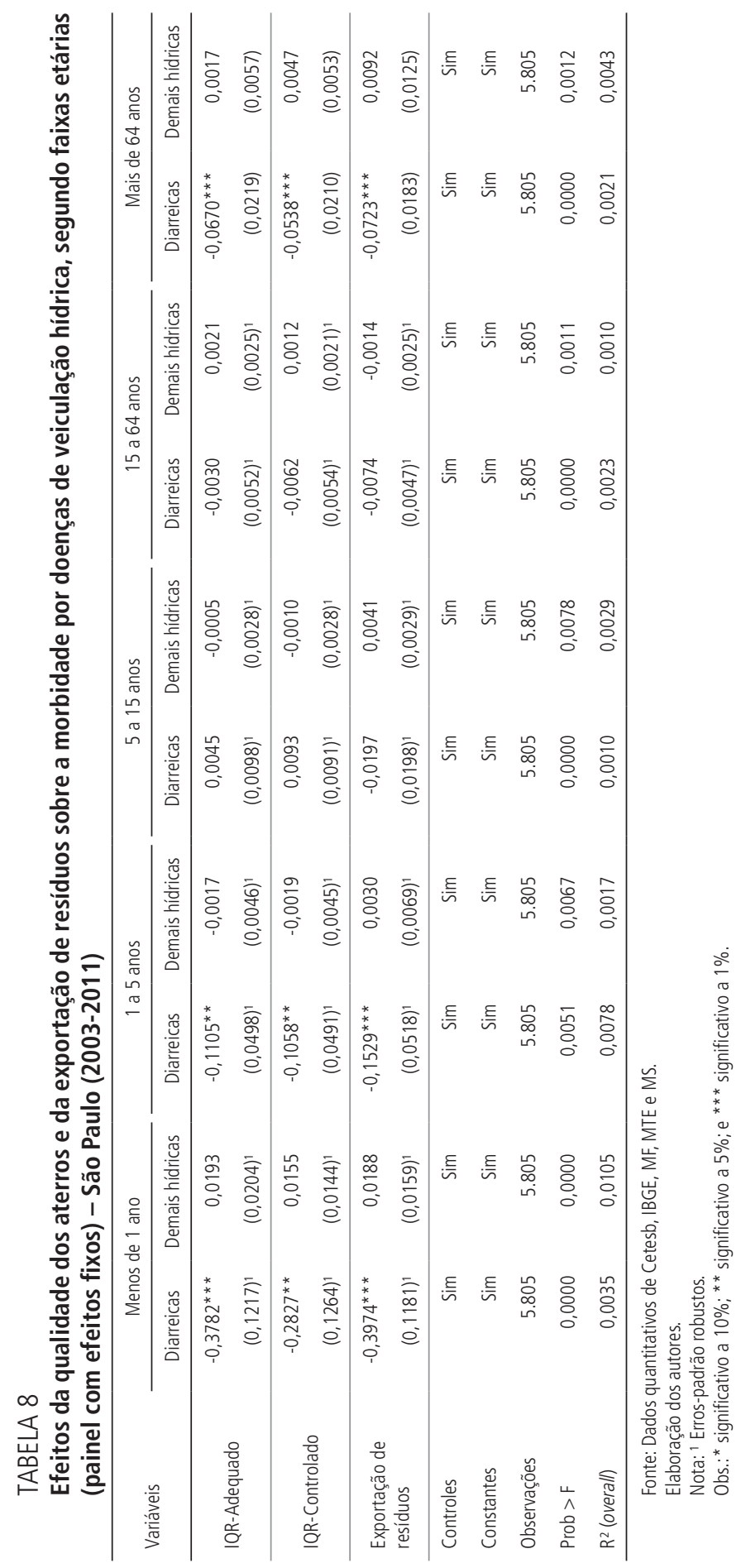




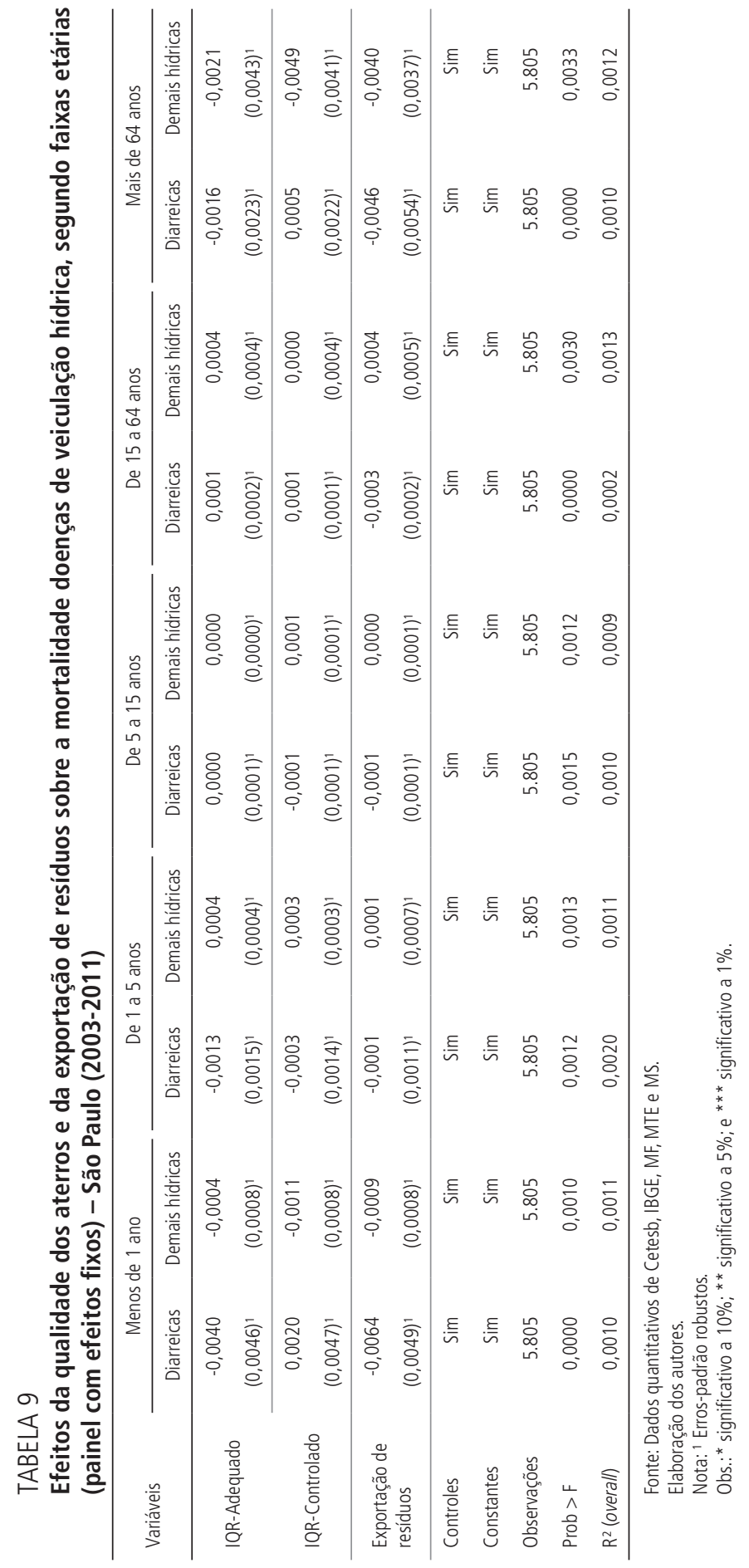


TABELA 10

Efeitos da qualidade dos aterros e da exportação de resíduos sobre a morbidade por outras doenças, segundo faixas etárias (painel com efeitos fixos) - São Paulo (2003-2011)

\begin{tabular}{lrrc}
\hline Variáveis & Menos de 1 ano & De 1 a 5 anos & Mais de 64 anos \\
\hline \multirow{2}{*}{ IQR-Adequado } & 0,1624 & 0,1390 & $-0,2502$ \\
& $(0,4209)^{1}$ & $(0,1296)^{1}$ & $(0,2877)^{1}$ \\
\hline IQR-Controlado & 0,4083 & 0,1068 & $-0,4847$ \\
& $(0,3970)^{1}$ & $(0,1193)^{1}$ & $(0,4962)^{1}$ \\
\hline \multirow{2}{*}{ Exportação de resíduos } & $-0,3737$ & $-0,1714$ & $-0,6626$ \\
& $(0,5044)^{1}$ & $(0,1627)^{1}$ & $(0,7673)^{1}$ \\
\hline Controles & Sim & Sim & Sim \\
Constantes & Sim & Sim & 5.805 \\
Observações & 5.805 & 5.805 & 0,0000 \\
Prob $>$ F & 0,0000 & 0,0015 & 0,0046 \\
R2 (overall) & 0,0050 & 0,0048 & \\
\hline
\end{tabular}

Fonte: Dados quantitativos de Cetesb, IBGE, MF, MTE e MS.

Elaboração dos autores.

Nota: ${ }^{1}$ Erros-padrão robustos.

Obs.: ${ }^{*}$ significativo a $10 \%$; ${ }^{* *}$ significativo a $5 \%$; e ${ }^{* * *}$ significativo a $1 \%$.

\section{CONSIDERAÇÕES FINAIS}

Este artigo investiga os efeitos da disposição final ambientalmente adequada dos resíduos sólidos urbanos sobre as condiçóes de saúde dos indivíduos, medidas por indicadores municipais de morbidade hospitalar (internaçóes por 100 habitantes) e de mortalidade (óbitos por 100 habitantes). Para isso, são testadas as hipóteses de que a existência de aterros sanitários, a qualidade das instalações de disposição final dos resíduos urbanos e a exportação destes resíduos impactariam positivamente sobre os indicadores municipais de morbimortalidade. As evidências encontradas, por meio de estimaçōes econométricas, não refutam as três hipóteses.

Primeiramente, pode-se inferir que a existência de aterro sanitário em um município afeta positivamente a saúde de seus residentes. Tal afirmação é subsidiada pelos resultados obtidos por estimaçóes por $\mathrm{MQO}$, que abrangem todos os municípios brasileiros com dados disponíveis referentes ao ano de 2008. Os resultados sinalizam efeitos médios negativos e significativos, associados à existência de aterro sanitário sobre a morbidade hospitalar e a mortalidade, no total, nas doenças mais direta e imediatamente afetadas pela situação da disposição final dos resíduos (diarreicas) e em segmento etário (de 1 a 5 anos), dentro da faixa de idade mais vulnerável. Ademais, não são constatados efeitos significativos no mesmo segmento etário em doenças que a literatura não associa diretamente à situação da disposição final dos resíduos urbanos, tanto na morbidade como na mortalidade. Assim, pela estratégia de identificação adotada, as relaçóes encontradas podem ser 
interpretadas, com relativa robustez, como efeitos causais dos aterros sobre a saúde. No entanto, por estimaçóes em painel por efeitos fixos com dados anuais dos municípios paulistas referentes ao período de 2003 a 2011, os resultados sinalizam que a qualidade das instalaçōes de disposição final dos resíduos sólidos urbanos e a exportação destes resíduos para instalaçôes em outros municípios impactam positivamente sobre a saúde da população residente e, desta maneira, melhoram indicadores municipais de saúde. Neste caso, são observados efeitos significativos e negativos somente na morbidade hospitalar, inclusive nas doenças mais direta e imediatamente afetadas pela situação da disposição de resíduos (diarreicas) e na faixa etária mais vulnerável (até 5 anos). Assim, é possível atribuir, com certa robustez, causalidade aos efeitos estimados.

Conjuntamente, os resultados obtidos sinalizam que a disposição final ambientalmente adequada dos resíduos sólidos urbanos resulta em impactos positivos sobre as condiçóes de saúde das pessoas e, consequentemente, melhora indicadores municipais de saúde. Dessarte, este estudo contribui para a literatura empírica e apresenta evidências que sinalizam a importância da disposição final adequada dos resíduos sólidos urbanos para as políticas públicas. Trata-se de um serviço com externalidades ambientais e sobre a saúde pública. No curto prazo, pode afetar gastos públicos e impor privaçôes à saúde, restringindo as capacitaçôes individuais; no longo prazo, pode impactar dimensóes dos pilares relevantes para o desenvolvimento sustentável. Assim, no Brasil, a disposição ambientalmente adequada dos resíduos urbanos é um importante desafio para as políticas públicas, pois, apesar de estarem proibidas desde 2014 pela Lei dos Resíduos Sólidos, ainda predominam as disposições finais em "lixões" e aterros controlados.

Vale ressaltar que a busca por formas de acondicionamento, gerenciamento e até mesmo redução da geração de resíduos é um desafio multidisciplinar com implicaçōes de longo prazo. As premissas que norteiam essa preocupação são: a de que o desenvolvimento humano requer o equacionamento de privaçóes à vida plena, as quais podem decorrer de vulnerabilidades ambientais; e que tais vulnerabilidades e suas consequências, em especial sobre a saúde, são influenciadas pela disposição final dos resíduos urbanos e determinam o desenvolvimento sustentável.

Nesse sentido, outro conjunto de contribuiçóes deste estudo reside nas formas como se busca operacionalizar as complicadas relaçóes entre disposição final dos resíduos e qualidade de vida, via impactos na saúde. Do ponto de vista de técnicas de pesquisa, se destaca o uso de critérios para a especificação das variáveis relevantes pela literatura de saúde, e não somente econômica. Ao empregar critérios da área de saúde para aplicação de instrumentos de avaliação tradicionais da economia, sinaliza não somente possibilidades de aproximação entre as áreas, mas permite a ambas uma ampliação das alternativas de comprovação empírica 
para assertivas do senso comum, como: "resíduos sólidos prejudicam a saúde, sobretudo de crianças e idosos".

Ademais, a investigação da relação entre possibilidade de exportação de resíduos e saúde da população residente reforça um conjunto complexo de preocupaçóes acerca da forma de gerenciamento e acondicionamento dos resíduos sólidos urbanos frente à escassez de espaços para aterros sanitários em algumas localidades. Assim, uma possível agenda de pesquisa a ser seguida a partir deste estudo é a importância de estratégias de governança e análises políticas dos vários interesses conflitantes que permeiam a ocupação e utilização dos espaços, sobretudo em grandes centros urbanos. Outra possível agenda de pesquisa futura refere-se à valoração dos custos socioeconômicos da disposição inadequada de resíduos, o que pode subsidiar escolhas dos agentes públicos e privados e incentivar processos produtivos com minimizaçáo de dejetos.

\section{REFERÊNCIAS}

ABRELPE - ASSOCIAÇÃO BRASILEIRA DE EMPRESAS DE LIMPEZA PÚBLICA E RESÍDUOS ESPECIAIS. Panorama dos Resíduos Sólidos no Brasil 2016. São Paulo: Abrelpe, 2016.

ALDERMAN, H. et al. Child nutrition, child health and school enrollment: a longitudinal analysis. Washington, D.C.: World Bank, 1997. (Policy Research Working Paper, n. 1.700).

ANGRIST, J. D.; PISCHKE, J. S. Mostly harmless econometrics: an empiricist's companion. Princeton: Princeton University Press, 2009.

AZEVEDO, M. A.; AZEVEDO, E. A.; HELLER, L. Bases metodológicas para o desenvolvimento de uma classificação ambiental para as doenças relacionadas aos resíduos sólidos. In: CONGRESSO INTERAMERICANO DE ENGENHARIA SANITÁRIA E AMBIENTAL, 27., Porto Alegre, Rio Grande do Sul, 2000. Anais... Porto Alegre: Abes, 2000.

BALTAGI, B. H. Econometric analysis of panel data. New Jersey: Wiley and Sons Ltda., 2001.

BANERJEE, A. V.; DUFLO, E. A. Economia dos pobres. 1. Ed. Lisboa: Temas e Debates, 2011.

BITTENCOURT, S. A.; CAMACHO, L. A. B.; LEAL, M. C. O sistema de informação hospitalar e sua aplicação na saúde coletiva. Cadernos de Saúde Pública, v. 22, n. 1, 2006. 
BRASIL. Sistemas de informação em saúde e vigilância epidemiológica. Brasília: MS, 2005.

. Lei Federal no 11.445, de 5 de janeiro de 2007. Estabelece as diretrizes nacionais para o saneamento básico e para a política federal de saneamento básico. Brasília: Congresso Nacional, 2007.

. Lei Federal no 12.305, de 2 de agosto de 2010. Institui a Política Nacional de Resíduos Sólidos; altera a Lei no 9.605, de 12 de fevereiro de 1998; e dá outras providências. Brasília: Congresso Nacional, 2010.

BRISCOE, J.; FEACHEM, R. G.; RAHAMAN, M. M. Evaluating health impact; water supply, sanitation, and hygiene education. Ottawa: International Development Research Centre, 1986.

BURAI, W. A. S.; SAIANI, C. C. S.; KUWAHARA, M. Y. Existência de aterros sanitários nos municípios brasileiros: determinantes socioeconômicos e impactos sobre a saúde. In: XVII ENCONTRO NACIONAL DE ECONOMIA POLÍTICA, 17,. Porto Alegra, Rio Grande do Sul, 2012. Anais... Porto Alegre: UFRGS, 2012.

CAIRNCROSS, S.; FEACHEM, R. G. Environmental health engineering in the tropics: an introductory text. Chichester: John Wiley \& Sons, 1990.

CALDWELL, J. C. Cultural and social factors influencing mortality levels in developing countries. American Academy of Political and Social Science, v. 510, p. 44-5, 1990.

CAMPOS, H. K. T. Renda e evolução da geração per capita de resíduos sólidos no Brasil. Engenharia Sanitária Ambiental, v. 17, n. 2, 2012.

CAVALCANTI, C. Condicionantes biofísicos da economia e suas implicações quanto à noção do desenvolvimento sustentável. In: ROMEIRO, A. R.; REYDON, B. P; LEORNARDI, M. L. A. Economia do meio ambiente. Campinas: Unicamp, 1997.

COSTANZA, R. Ecological Economics: the science and management of sustainability. New York: Columbia University Press, 1991.

CVJETANOVIC, B. Health effects and impact of water supply and sanitation. World Health Statistics Quarterly, v. 39, n. 1, p. 105-117, 1986.

DALY, H.; FARLEY, H. Ecological Economics: principles and applications. 2. Ed. Washington, D.C.: Island Press, 2010.

DAVID, O. M.; OLUYEGE, A. O. Effect of open refuse dumpsite on the quality of underground water used for domestic purposes in AdoEkiti, Nigeria - a public health awareness study. Journal of Environment and Ecology, v. 5, n. 2, 2014. 
DIAS, D. M. et al. Modelo para estimativa da geração de resíduos sólidos domiciliares em centros urbanos a partir de variáveis socioeconômicas conjunturais. Engenharia Sanitária Ambiental, v. 17, n. 3, jul./set. 2012.

ESREY, S. A. et al. Health benefits from improvements in water supply and sanitation: survey and analysis of the literature on selected diseases. Washington, D.C.: Wash, 1990. (Wash Technical Report, n. 66).

FEAM - FUNDAÇÃO ESTADUAL DO MEIO AMBIENTE. Orientaçóes básicas para a operaçáo de aterro sanitário. Belo Horizonte: Feam, 2006.

FERREIRA, J. A.; DOS ANJOS, L. A. Aspectos de saúde coletiva e ocupacional associados à gestão dos resíduos sólidos municipais. Cadernos de Saúde Pública, Rio de Janeiro, v. 17, n. 3, 2001.

FORATTINI. O. P. Aspectos epidemiológicos ligados ao lixo. São Paulo: USP; FSP; OMS; OPAS, 1969.

FUNASA - FUNDAÇÃO NACIONAL DE SAÚDE. Textos de Epidemiologia para vigilância ambiental em saúde. Brasília: Funasa; MS, 2002.

GALIANI, S.; GERTLER, P.; SCHARGRODSKY, E. Water for life: the impact of the privatization of water services on child mortality. Journal of Political Economy, v. 113, n. 1, 2005.

GEIB, L. T. C. Determinantes sociais da saúde do idoso. Ciência e Saúde Coletiva, v. 17, n. 1, p.123-133, 2012.

GLEWWE, P.; JACOBY, H. G. An economic analysis of delayed primary school enrollment in a low-income country: the role of early childhood nutrition. The Review of Economics and Statistics, v. 77, n. 1, p. 156-169, 1995.

GOLDMAN, L. R. et al. Low birth weight, prematurity and birth defects in children living near the hazardous waste site, Love Canal. Hazardous Waste and Hazardous Materials, v. 2, n. 2, p. 209-223, 1985.

GOMES, M. G.; MACDOWELL, C. M. Descentralização política; federalismo fiscal e criaçáo de municípios: o que é mau para o econômico nem sempre é bom para o social. Brasília: Ipea, 2000. (Texto para Discussão, n. 706).

GOUVEIA, N. Resíduos sólidos urbanos: impactos socioambientais e perspectiva de manejo sustentável com inclusão social. Ciência \& Saúde Coletiva, v. 17, n. 6, 2012.

GRADSTEIN, M.; JUSTMAN, M. The democratization of political elites and the decline inequality in modern economic growth. In: BREZIS, E.; TEMIN, P. (Eds.). Elites, minorities and economic growth. Amsterdam: Elsevier, 1999. 
GREENE, W. H. Econometric analysis. 3. Ed. New Jersey: Prentice Hall, 1997. GRISA, D. C.; CAPANEMA, L. Resíduos sólidos. In: BNDES - BANCO NACIONAL DE DESENVOLVIMENTO ECONÔMICO E SOCIAL. Visáo 2035: Brasil, país desenvolvido - agendas setoriais para o alcance da meta. Brasília: BNDES, 2018

GUERRIERO, C.; CAIRNS, J. The potential monetary benefits of reclaiming hazardous waste sites in the Campania region: an economic evaluation. Environmental Health, v. 8, n. 28, 2009.

HELLER, L. Saneamento e saúde. Brasília: Organização Pan-Americana da Saúde, 1997.

HELLER, L.; CATAPRETA, C. A. A. Metodologia para avaliação do impacto dos resíduos sólidos domésticos sobre a saúde de uma população. CONGRESSO BRASILEIRO DE ENGENHARIA SANITÁRIA E AMBIENTAL, 19., Foz do Iguaçu, Santa Catarina, 1997. Anais... Foz do Iguaçu: Abes, 1997.

IBAMA - INSTITUTO BRASILEIRO DO MEIO AMBIENTE E DOS RECURSOS NATURAIS RENOVÁVEIS. Instruçáo Normativa no 13. Brasília: Ibama; MMA, 2012.

LAURENTI, R.; MELLO JORGE, M. H. P.; GOTLIEB, S. L. D. A confiabilidade dos dados de mortalidade e morbidade por doenças crônicas não-transmissíveis. Ciência \& Saúde Coletiva, v. 9, n. 4, p. 909-920, 2004.

MARA, D. D.; FEACHEM, R. G. A. Water and excreta related diseases: unitary environmental classification. Journal of Environmental Engineering, v. 125, n. 4, 1999.

MARTINEZ-ALIER, J.; ROCA, J. Economía ecológica y política ambiental. Ciudad de Mexico: FCE, 2005.

MARTUZZI, M.; MITIS, F.; FORASTIERE, F. Inequalities, inequities, environmental justice in waste management and health. European Journal of Public Health, v. 20, n. 1, p. 21-26, 2010.

MATHIAS, T. A. F.; SOBOLL, M. L. M. S. Confiabilidade de diagnósticos nos formulários de autorização de internação hospitalar. Saúde Pública, v. 32, n. 6, p. 526-532, 1998.

MAVROPOULOS, A. Saúde desperdiçada: o caso dos lixôes. Viena: ISWA, 2015.

NUSSBAUM, M. C. Creating capabilities: the human development approach. Cambridge: Harvard University, 2011. 
NUSSBAUM, M. C.; SEN, A. (Orgs.). La calidad de vida. Ciudad de Mexico: FCE, 1996.

OLIVEIRA. W. E. Socio economic, environmental and health implications of solid wastes. St. Domingo: Regional Simposium Solid Wastes, 1978.

OMRAM, A. R. The epidemiologic transition: a theory of the epidemiology of population change. Bulletin the World Health Organization, v. 49, n. 4, p. 509-538, 2001.

OXLEY, H.; MARTIN, J. P. Controlling government spending and deficit: trends in the 1980s and prospects for the 1990s. OECD Economic Studies, v. 2, 1991.

ROBEYNS, I. The capability approach: a theoretical survey. Journal of Human Development and Capabilities, v. 6, n. 1, p. 93-117, 2005.

ROMEIRO, A. R. Economia ou economia política da sustentabilidade. In: MAY, P.; LUSTOSA, M. C.; VINHA, V. Economia do meio ambiente. Rio de Janeiro: Campus, 2003.

ROY, A. D. Some thoughts on the distribution of earnings. Oxford Economic Papers, v. 3, n. 3, p. 135-146, 1951.

RUBIN, D. B. Estimating causal effects of treatments in randomized and nonrandomized studies. Journal of Educational Psychology, v. 66, n. 5, p. 688$701,1974$.

SCHRAMM, J. M. A. et al. Transição epidemiológica e o estudo de carga de doenças no Brasil. Ciência \& Saúde Coletiva, v. 4, n. 4, 2004.

SCRIMSHAW, N. S.; TAYLOR, C. E.; GORDON, J. E. Interactions of nutrition and infection. Geneva: WHO, 1968. (World Health Organization Monograph Series, n. 57).

SEN, A. K. Capacidad y bienestar. In: NUSSBAUM, M. C.; SEN, A. (Orgs.). La calidad de vida. Ciudad de Mexico: FCE, 1996.

Desenvolvimento como liberdade. São Paulo: Companhia das Letras, 2000.

. Desigualdade reexaminada. Rio de Janeiro: Record, 2001.

SILVA, S. P. A organização coletiva de catadores de material reciclável no Brasil: dilemas e potencialidades sob a ótica da economia solidária. Brasília: Ipea, jan. 2017. (Texto para Discussão, n. 2268).

SOUZA, I. V.; NISHIJIMA, M.; ROCHA, F. Eficiência do setor hospitalar nos municípios paulistas. Economia Aplicada, v. 14, n. 1, p. 51-66, 2010. 
SU, G. S. Waterborne illness from contaminated drinking water sources in close proximity to a dumpsite in Payatas, The Philippines. Journal of Rural and Tropical Public Health, v. p. 43-48, 2005.

VICTORA, C. G.; GRASSI, P. R.; SCHMIDT, A. M. Situação de saúde da criança em área da região sul do Brasil, 1980-1992: tendências temporais e distribuição espacial. Saúde Pública, v. 28, n. 6, 1994.

WANG, L. Determinants of child mortality in LDCs: empirical findings from demographic and health surveys. Health Policy, v. 65, n. 3, p. 277-299, 2003.

WENNEMO, I. Infant mortality, public policy and inequality - a comparison of 18 industrialized countries". Sociology of Health \& Illness, v. 15, n. 4, 1993. 


\section{APÊNDICE A}

\section{TABELA A. 1}

Estatísticas descritivas das variáveis de controle $\left(\mathbf{X}_{\mathbf{i}}\right)$ - Brasil (2008)

\begin{tabular}{|c|c|c|c|c|}
\hline Variáveis & Média & Desvios-padrão & Mínimos & Máximos \\
\hline Lixo & 0,6611 & 0,2245 & 0,0000 & 0,9995 \\
\hline Água & 0,6694 & 0,2011 & 0,0000 & 0,9996 \\
\hline Esgoto & 0,2873 & 0,3102 & 0,0000 & 0,9974 \\
\hline PIB per capita & 5,3894 & 6,1067 & 0,8910 & 149,2704 \\
\hline População & 0,0343 & 0,2013 & 0,0008 & 10,9903 \\
\hline População - menos de 1 ano & 0,0006 & 0,0028 & 0,0001 & 0,1507 \\
\hline População - de 1 a 5 anos & 0,0023 & 0,0120 & 0,0001 & 0,6528 \\
\hline População - de 5 a 15 anos & 0,0061 & 0,0319 & 0,0001 & 1,7141 \\
\hline População - de 15 a 64 anos & 0,0230 & 0,1398 & 0,0006 & 7,6502 \\
\hline População - mais de 64 anos & 0,0023 & 0,0154 & 0,0001 & 0,8223 \\
\hline Densidade & 0,1119 & 0,6054 & 0,0001 & 13,7738 \\
\hline Fundamental & 0,7082 & 0,1342 & 0,1125 & 1,0000 \\
\hline Terciário & 0,2443 & 0,1789 & 0,0030 & 1,0000 \\
\hline Meritórios & 0,7018 & 0,1094 & 0,2945 & 1,3810 \\
\hline Bem-estar & 0,0641 & 0,0348 & 0,0001 & 0,2749 \\
\hline Imunização & 0,8265 & 0,1167 & 0,3919 & 2,2026 \\
\hline Leitos do SUS & 0,0675 & 0,4051 & 0,0000 & 17,5250 \\
\hline Outros leitos & 0,0108 & 0,1607 & 0,0000 & 8,7480 \\
\hline
\end{tabular}

Fonte: Dados quantitativos de IBGE, MF, MS e MTE.

Elaboração dos autores. 
TABELA A.2

Estatísticas descritivas das variáveis de controle $\left(\mathbf{X}_{\mathrm{it}}\right)$ - São Paulo (2003-2011)

\begin{tabular}{|c|c|c|c|c|}
\hline Variáveis & Média & Desvios-padrão & Mínimos & Máximos \\
\hline Lixo & 0,8792 & 0,1047 & 0,1264 & 1,0000 \\
\hline Água & 0,8400 & 0,1236 & 0,2260 & 1,0000 \\
\hline Esgoto & 0,7595 & 0,1957 & 0,0000 & 1,0000 \\
\hline PIB per capita & 8,2209 & 7,2329 & 2,0419 & 107,5387 \\
\hline População & 0,0620 & 0,4442 & 0,0008 & 11,3124 \\
\hline População - menos de 1 ano & 0,0010 & 0,0067 & 0,0001 & 0,1857 \\
\hline População - de 1 a 5 anos & 0,0040 & 0,0273 & 0,0001 & 0,7429 \\
\hline População - de 5 a 15 anos & 0,0104 & 0,0700 & 0,0001 & 1,8090 \\
\hline População - de 15 a 64 anos & 0,0435 & 0,3095 & 0,0005 & 8,0463 \\
\hline População - mais de 64 anos & 0,0043 & 0,0319 & 0,0001 & 0,9202 \\
\hline Densidade & 0,2921 & 1,1607 & 0,0037 & 12,6350 \\
\hline Fundamental & 0,6889 & 0,1336 & 0,1136 & 1,7393 \\
\hline Terciário & 0,3254 & 0,1949 & 0,0053 & 3,3956 \\
\hline Meritórios & 0,7245 & 0,1264 & 0,3432 & 3,8127 \\
\hline Bem-estar & 0,0775 & 0,0389 & 0,0000 & 0,5268 \\
\hline Imunização & 0,8061 & 0,1119 & 0,3261 & 2,1944 \\
\hline Leitos SUS & 0,1107 & 0,6883 & 0,0000 & 17,5250 \\
\hline Outros leitos & 0,0362 & 0,3910 & 0,0000 & 13,8540 \\
\hline
\end{tabular}

Fonte: Dados quantitativos de IBGE, MF, MS e MTE.

Elaboração dos autores.

Data da submissão: 15/4/2018

Aprovação final em: 30/10/2018

Aprovação direta, sem necessidade de correçôes. 
